\title{
Open Space as Evacuation Areas on Super Levees along the Arakawa River, Japan
}

\author{
Nurul Ashikin Mabahwi ${ }^{1}$, Hitoshi Nakamura ${ }^{2}$, Yasmin Bhattacharya ${ }^{3}$
}

\author{
${ }^{1}$ Graduate School of Engineering and Science, \\ 2Department of Planning, Architecture and Environment Systems, \\ ${ }^{3}$ SIT Research Laboratories, \\ Shibaura Institute of Technology, Japan \\ na18102@shibaura-it.ac.jp, nakamu-h@shibaura-it.ac.jp, yasmin@shibaura-it.ac.jp
}

\begin{abstract}
The objective of this study is to re-evaluate the conceptualisation of super levees by focussing on the availability of open spaces as evacuation areas along the Arakawa River. By using land use, occupation and cross-section analysis, this study found that open spaces on super levees able to accommodate a large number of evacuees. This proves that the development of super levees is undeniably ready to provide sizeable safe upland evacuation area for nearby residents. This study also implies that the future development of super levee should include more open space by the development of a public park on the site.
\end{abstract}

Keywords: super levee; open space; flood; evacuation

eISSN 2514-751X @ 2019. The Authors. Published for AMER, ABRA \& cE-Bs by E-International Publishing House, Ltd., UK. This is an open-access article under the CC BY-NC-ND license (http://creativecommons.org/licenses/bync-nd/4.0/). Peer-review under responsibility of AMER (Association of Malaysian Environment-Behaviour Researchers), ABRA (Association of Behavioural Researchers on Asians) and cE-Bs (Centre for EnvironmentBehaviour Studies), Faculty of Architecture, Planning \& Surveying, Universiti Teknologi MARA, Malaysia.

DOI: https://doi.org/10.21834/aje-bs.v4i14.353 


\subsection{Introduction}

The Eastern Lowland Districts of Tokyo face the risk of an urban flood disaster because the land area within the eastern Tokyo is roughly less than Arakawa Pail (A.P.) +5.1 metre. Since lowland is prone to flooding, in the year 1987, the River Council proposed a solution to protect the lower 58.2 kilometres of the river with high standard levees (super levees) (McKean, 2013). The River Council of Japan, in a report entitled 'Recommendations on Policies for Protection from Extreme Floods', proposed a policy for protection from extreme floods to protect specific urban areas (Arakawa Karyu River Office, 2007). These urban areas comprised of a concentration of significant property and business functions such as Tokyo. The policy is applicable for extreme floods, which exceed the design levels of the regular flood protection measures (Takahasi and Unitto, 2004 in Stalenberg and Kikumori, 2008). This specific policy includes super levees projects. The high standard levee improvement project (super levees project) started along six large rivers in Tokyo and Osaka, for example, Tonegawa, Edogawa, Arakawa, Tamagawa, Yodogawa and Yamatogawa (Nakamura, 2016).

Prior 1996 to 2010 super levees project was conducted in approximately 13 districts, while from the year 2011 onwards about 4 to 7 districts. The improvement of the super levees as of March 2017 was about $120 \mathrm{~km}$. Approximately $14 \mathrm{~km}$ (around 12\%) of the basic crosssection of the high standard levee. The section where the form is secured is about $3.3 \mathrm{~km}$ (about 2.8\%), MLIT (2017a). The super levees maintenance projects conducted along Edogawa River, Arakawa River, Tamagawa River, Yodogawa River and Yamato River (MLIT, 2017a). For Arakawa River, there are 14 completed super levees projects at Shinsuna, Komatsugawa, Hirai, Hirai 7-chome, Senju, Odai, Odai 1-chome, Miyagi, Shinden, Shikahama, Kawaguchi, Kita-Akabane, Funado and Toda Koen.

Since the low-lying area is vulnerable to disaster, the importance to thoroughly examine evacuation of these areas are much needed. The Cabinet Office emphasised the evacuation methods described in the current hazard map of each municipality in a low-lying area will not be useful in the case of delay in evacuation caused by public transportation congestion, or if the number of evacuees exceeds the capacity of each designated evacuation area (Nakamura, 2016). Also stated it is necessary to examine other evacuation methods, such as temporarily evacuating evacuees to the upper floor of a school building or an upland area created by a large-scale high-standard levee in the neighbourhood as temporary evacuation shelter (Nakamura, 2016).

A previous study found that, if Arakawa River in Shinden district (super levee area) is breached, people in the inundated area could evacuate to safe areas in the neighbourhood on the condition that an appropriate evacuation system is established (Nakamura, 2016). The study found that the number of estimated potential evacuees $(11,280)$ at night exceeds the number of estimated night time evacuees $(3,187)$, and the number of estimated potential evacuees $(11,610)$ in the daytime exceeds the number of estimated daytime evacuees $(2,148)$. Besides, the number of potential evacuees who can evacuate to safe places within an inundated area is only 2,925 at night and 3,256 in the daytime. Which means neighbourhood evacuation for each evacuee will be difficult unless upland areas created through such means as super levees projects. Otherwise speaking, super levee has 
contributed to the creation of a large scale neighbourhood evacuation area in Shinden district (Nakamura, 2016).

Equally important, Allan and Bryant (2010) emphasised the need to plan and design open space for cities to contribute to urban and disaster resilience. Leon and March (2014) highlighted that open space for the evacuation area should have terrain quality. Because the height of super levees ensures higher places for evacuation in case of inundation, open spaces in super levees are considered as evacuation area with terrain quality.

In referring to the advertised concept of super levees, it stated that super levees developed with open space as an evacuation area (Arakawa Karyu-River Office, 2007). This study starts with the assumption that not all developed super levees are equipped with open space for evacuation. Therefore, there is a need to re-evaluate the super levees' open space as an evacuation area.

\subsection{Objective of the study}

This study aimed to re-evaluate the conceptualisation of super levees by focusing on the availability of open spaces as evacuation areas. The study investigates available open spaces for evacuation in the vicinity of the super levees' boundary and determines the number of possible evacuees.

\subsection{Concept of the super levee}

High Standard Levee or super levee is a new type of levee that can withstand floods and earthquakes and built-in tandem with urban renovation projects (Arakawa-Karyu River Office, 2007). Conventional levees easily breached during massive floods that exceed reasonable forecasts. However, with super levees, the ground level of land on the city side along the river is raised. Super levees are extremely wide and capable of withstanding floodwaters. Even if the river overflows during significant flooding, the flood water spills out over gentle slopes, minimizing the damage to nearby urban areas and giving ample time to evacuate. Referring to Takeuchi (2002) in Luo et al., (2015), levee height is determined based on the maximum water level. Along Arakawa River, super levees area built approximately 10 metres high to protect Tokyo residents (Arakawa-Karyu River Office, 2017a).

The concepts of super levees development are, the wide must be 30 times more than its height (about $200 \mathrm{~m}$ to $300 \mathrm{~m}$ ). For example, the current height of levees should be 10 metres; therefore, the wide should be 300 metres with a gentler slope ration of 1:30.

Super levees must have easier access to the river; super levees embankments should link city streets to riverbanks with gently sloping hills (gentle slopes with a $3 \%$ gradient), not the steep climbs of raised levees for a more comfortable and enjoyable walk. Super levee too must be developed with emergency river road.

Other than that, the effective use of levee back slope for urban development. Once the ground level raised, the steep banks of the existing levee transformed into a flat open space that can put to a variety of uses (public roads, parks, evacuation areas). Super levees can also be evacuation sites when a disaster occurs because the height ensures a higher place 
for evacuation in case of inundation (Arakawa-Karyu River Office, 2007). Availability of these open spaces as evacuation areas gives residents greater peace of mind during floods and other disasters.

Super levees open up skylines that were blocked by conventional levees to give wide open views, reuniting people with the river's water and greenery and creating a pleasant living environment. Besides the ground improvement, due to upgrading from previous levee (conventional levee), the embanked soil of the super levee and ground is resistant to flooding and earthquake damage (Nakamura, 2016).

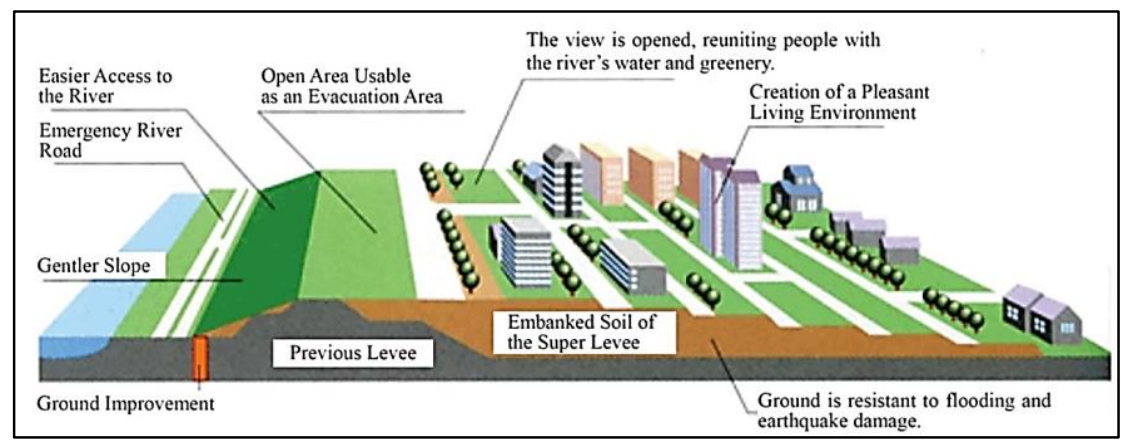

Figure 1: The concept of super levee

(Source: Arakawa-Karyu River Office, 2007)

\subsection{Summary for the effectiveness of the super levee}

'Overflow', 'permeation' and 'liquefaction' are the problems that can be overcome by the super levees. When the flood is unexpectedly in large scale, there is a danger of levee breach due to overflow. However, super levee helps in preventing levee breach by allowing water to overflow gently on levee slope. There is also a danger of levee breach due to permeation when the flood is in large scale. But super levees are able to prevent breach caused by destabilisation due to the levees' width being wider (MLIT, 2017b). Furthermore, urban area with soft ground could be damaged by liquefaction caused by a massive earthquake, but super levees are able to prevent such damage by soil stabilisation. For the anti-overtopping function, the levee's slope at the backside of the river is gradual compared to the normal levee, which reduces the flow rate of the water to improve the safety against levee collapse by overtopping (MLIT, 2017b).

Super levee is not intended to be effective only when $120 \mathrm{~km}$ of its maintenance section is completed, even if the basic cross-sectional shape not even completed, the levees still overflow, flood, permeation and liquefaction resistance (MLIT, 2017b).

In terms of the function of the super levees as an upland evacuation area, even if some sections of the super levees are well developed, the remaining sections (without super levee) can be flooded. In this case, there is a possibility of failure from conventional levee. Therefore, if there is a situation where the surrounding area is submerged, super levee can function as a base of various activities at the time of disasters such as for rescue, 
transportation and emergency supply. A super levee cannot be overtopped in the event of a large scale flood. So it can be utilised as a large scale upland evacuation area if open space can be provided.

\subsection{Methodology}

\subsection{Study area}

Along Arakawa River, there are 14 completed super levee projects at Shinsuna, Komatsugawa, Hirai and Hirai 7-chome, Senju, Odai, Odai 1-chome, Miyagi, Shinden, Shikahama, Kawaguchi, Kita Akabane, Funado and Toda Koen, refer Figure 2, and super levee in construction called Ukima. The areas chosen for this study are all completed super levee sites.

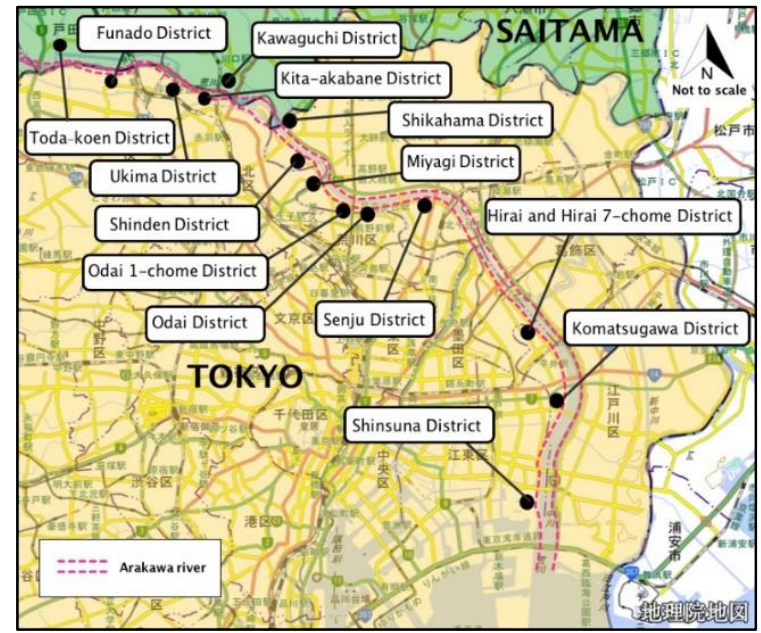

Figure 2: Super levee along Arakawa River (Source: maps.gsi.go.jp, 2019)

\subsection{Data collection}

This study started by visiting all super levee's site to make an observation and determined its land use. Interview at Arakawa-Karyu River Office was conducted to gather necessary information and data. ArcGIS and Geospatial Information Authority Japan (GSI) application used in obtaining levee's height and ground-level data.

\subsection{The analysis procedure}

The analysis for this study started with elevation and cross-section analysis by using GSI. 
Next, this study made land use analysis by using GIS to determine the type of land use and possible open space as an evacuation area. Followed by assumption analysis to exclude distraction of trees, shrubs and built-up facilities on the open space. Last, we made an occupancy analysis to determine the number of evacuees.

\subsection{Findings}

\subsection{Elevation and width of the super levee}

By using GIS and GSI data, this study examined the super levee districts cross-sectionally to determine the elevation and ensuring the height is according to the concept and suitable to be 'upland' evacuation area. Five areas built with levee's height less than 10 metres. Table 1 shows the size and height of each super levee's district:

Table 1: Height and wide of super levees

\begin{tabular}{lrr}
\hline Super levee districts & $\begin{array}{l}\text { Horizontal distance (width } \\
\text { metre) }\end{array}$ & Height (metre) \\
\hline Shinsuna & 123 & 7.9 \\
Komatsugawa & 98 & 7.4 \\
Hirai & 40 & 6.5 \\
Hirai 7-chome & 130 & 6.5 \\
Senju & 100 & 10.1 \\
Odai & 40 & 6.9 \\
Odai 1-chome & 189 & 10.5 \\
Miyagi & 40 & 10.3 \\
Shinden & 181 & 10.3 \\
Shikahama & 113 & 10.9 \\
Kawaguchi & 95 & 11.4 \\
Kita Akabane & 40 & 11.2 \\
Funado & 86 & 12.2 \\
Toda Koen & 147 & 10.3 \\
\hline Note: Horizontal distance is based on the average width; Height is based on Tokyo Pail (T.P) and the average \\
\multicolumn{2}{c}{ height of super levees }
\end{tabular}

\subsection{Land use of super levee's district}

By using GIS, this study made land use classification study of super levee's site along the Arakawa River. Land use categories of these super levee's site are four different types, residential, public park, public facilities and mixed development.

Shinsuna consists of open space, factory and commercial area. Komatsugawa consists of a large public park and mixed-use development. While Hirai and Hirai 7-chome, Odai and Shinden consist of a residential area. Senju, Kawaguchi, Kita Akabane and Funado correspond to public facilities. Miyagi, Shikahama and Toda Koen in the category of public park type. Last but not least, Odai 1-chome classified as mixed-use development, refer to Figure 3 until 41.

The total area size for Shinsuna is 18 hectare, area size for Komatsugawa is 23.3 hectares, 1.5 hectares for Hirai and Hirai 7-chome, 1.0 hectare for Senju, 0.4 hectares for 
Odai, 6.8 hectares for Odai 1-chome, 1.2 hectares for Miyagi, 26.58 hectares for Shinden, 3.4 hectares for Shikahama, 11.5 hectares for Kawaguchi, 2.0 hectares for Kita Akabane, 0.6 hectares for Funado, and 2.2 hectares for Toda Koen. Land use classification helps in determining open space designated to be evacuation area. However, this study found that not all area was developed with open space to be evacuation area (though the concept claimed so). For example, Hirai and Hirai 7-chome, Senju, Odai, Odai 1-chome and Funado were not designed with open space as an evacuation area. Hence, open space as an evacuation area compromises only 5 out of 10 areas. In this case, it is wise to consider roads as small scale dispersed evacuation spaces. The results of land use analysis, as shown in Table 2.

Table 2: Land use of super levee's district

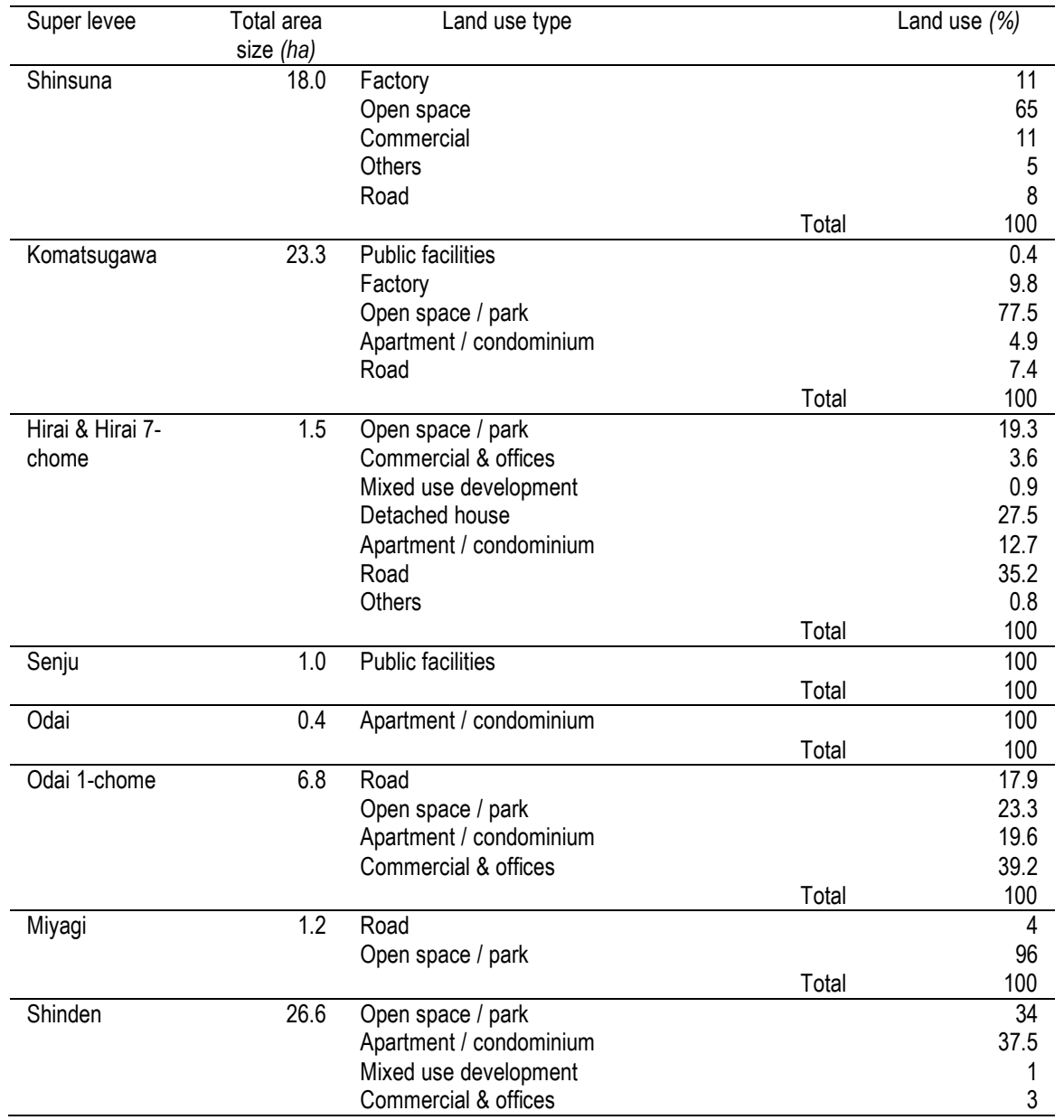


Mabahwi, N.A., et.al. / Asian Journal of Environment-Behaviour Studies (ajE-Bs), 4(14) Sep / Dec 2019 (pp.21-52)

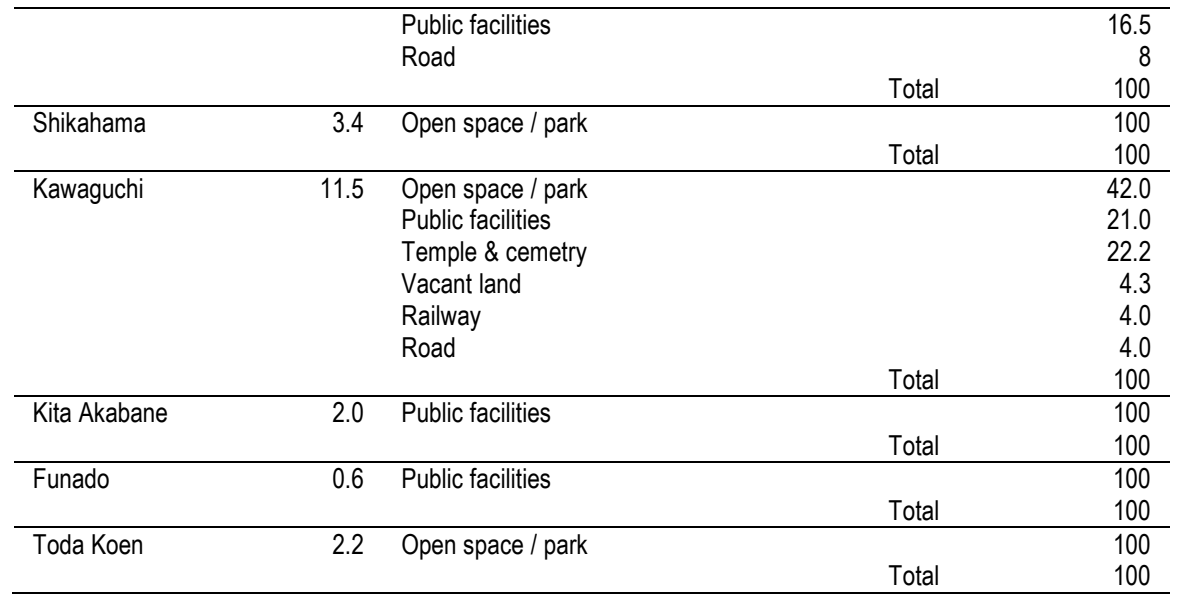

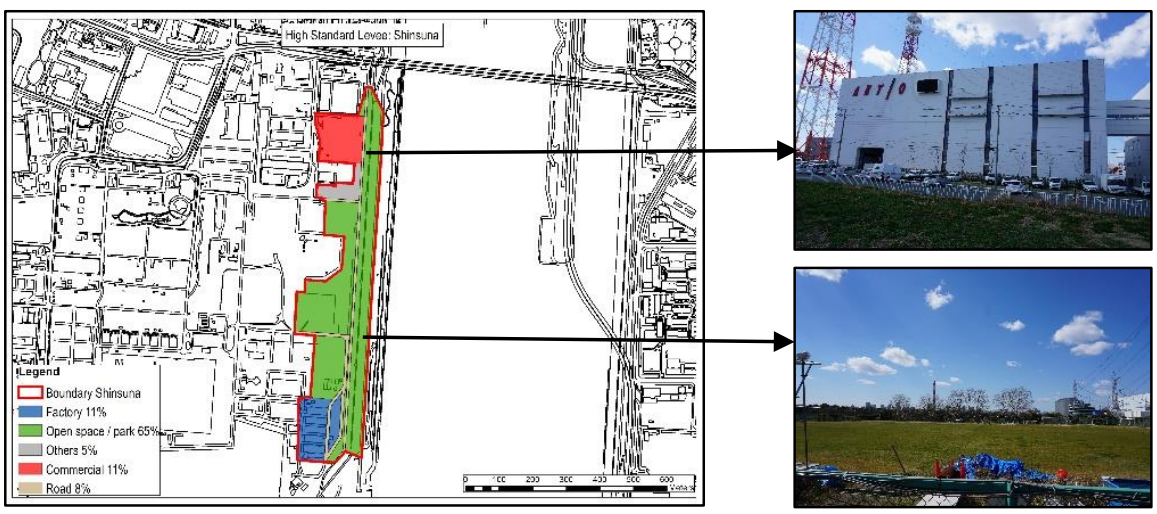

Figure 3: Land use of Shinsuna 


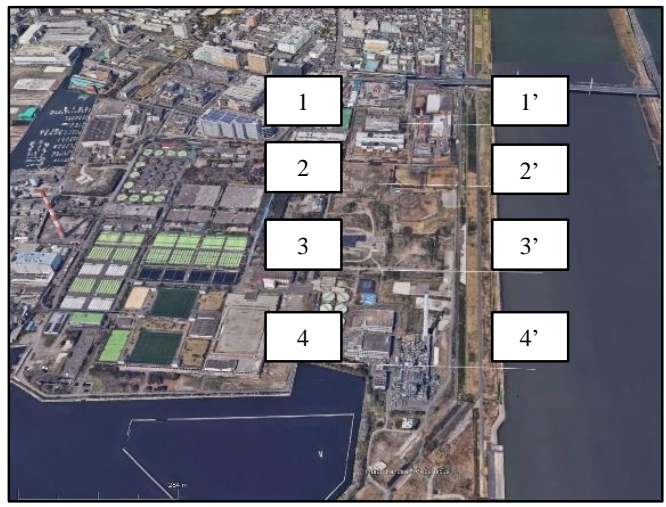

Figure 4: Cross section of Shinsuna
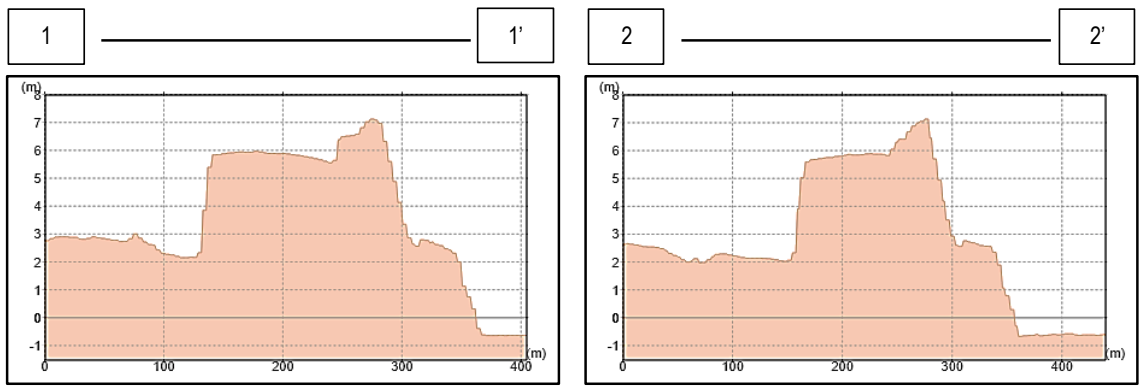

Figure 5: Elevation profile 1 and 2 of Shinsuna
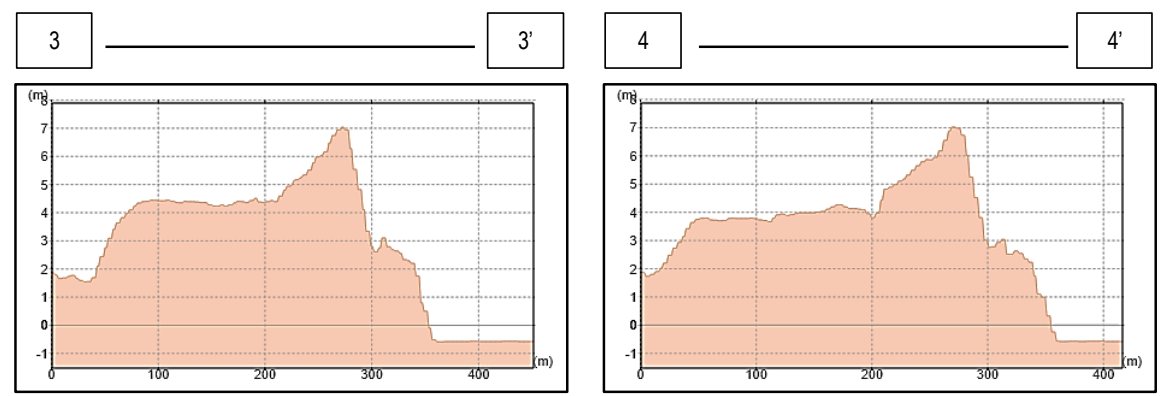

Figure 6: Elevation profile 3 and 4 of Shinsuna 

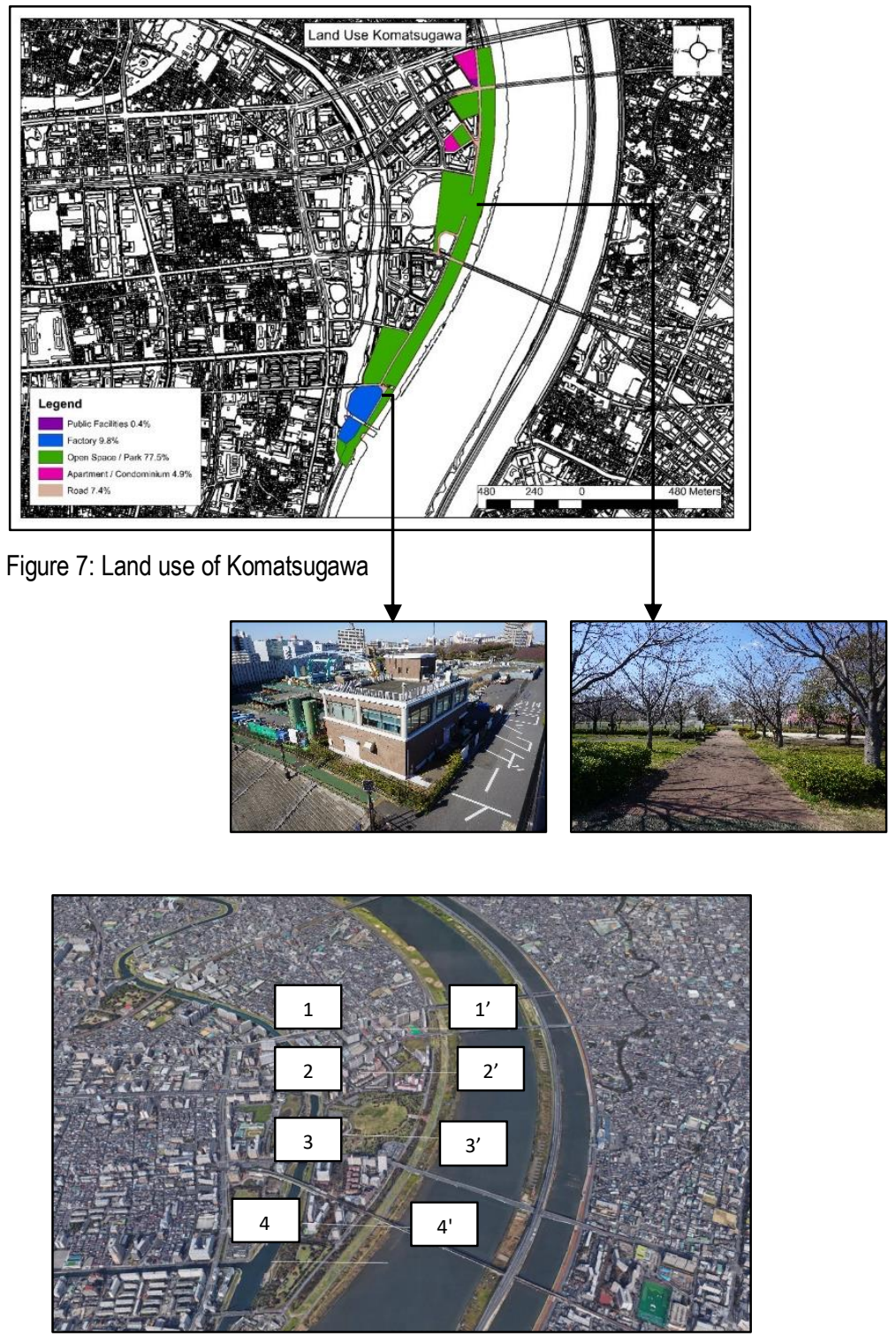

Figure 8: Cross section of Komatsugawa 
Mabahwi, N.A., et.al. / Asian Journal of Environment-Behaviour Studies (ajE-Bs), 4(14) Sep / Dec 2019 (pp. 21-52)
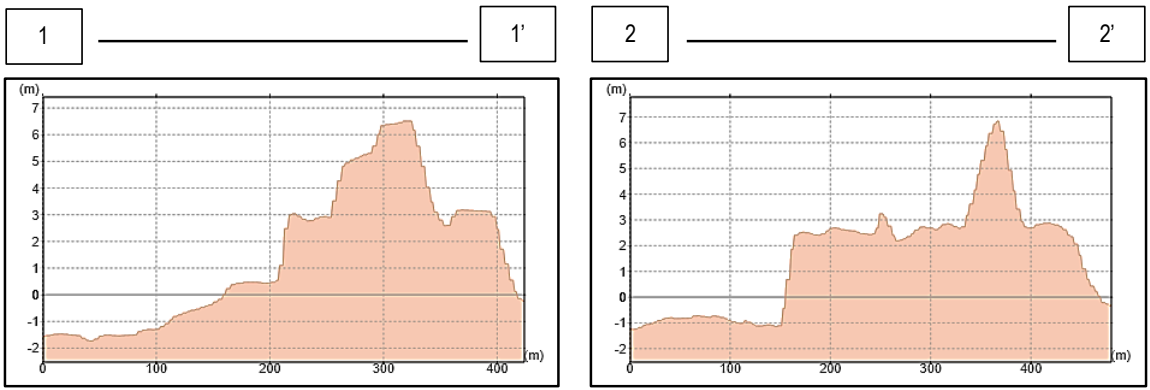

Figure 9: Elevation profile 1 and 2 of Komatsugawa
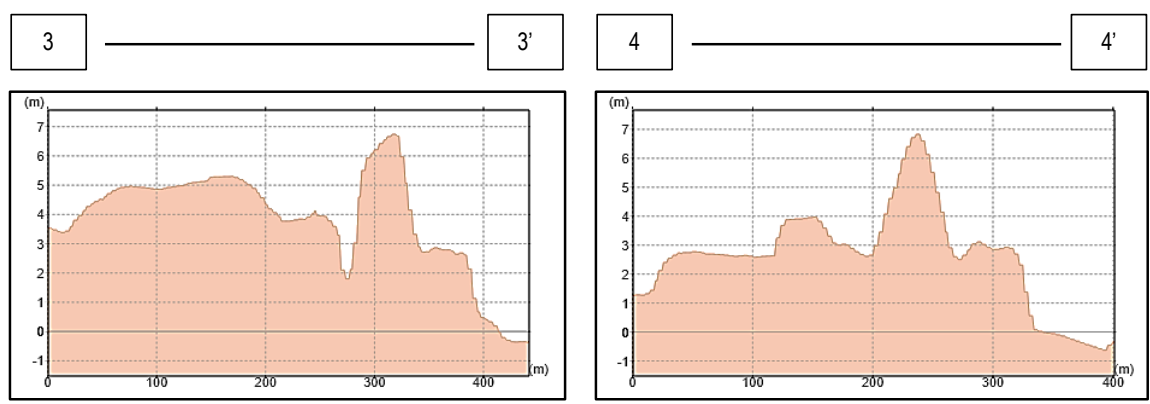

Figure 10: Elevation profile 3 and 4 of Komatsugawa 
Mabahwi, N.A., et.al. / Asian Journal of Environment-Behaviour Studies (ajE-Bs), 4(14) Sep / Dec 2019 (pp.21-52)

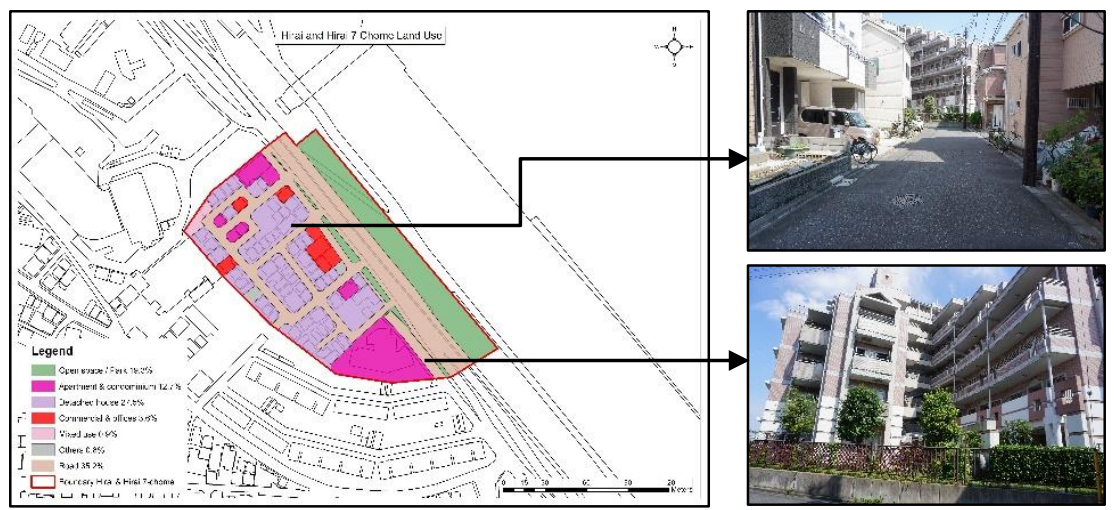

Figure 11: Land use of Hirai \& Hirai 7-chome

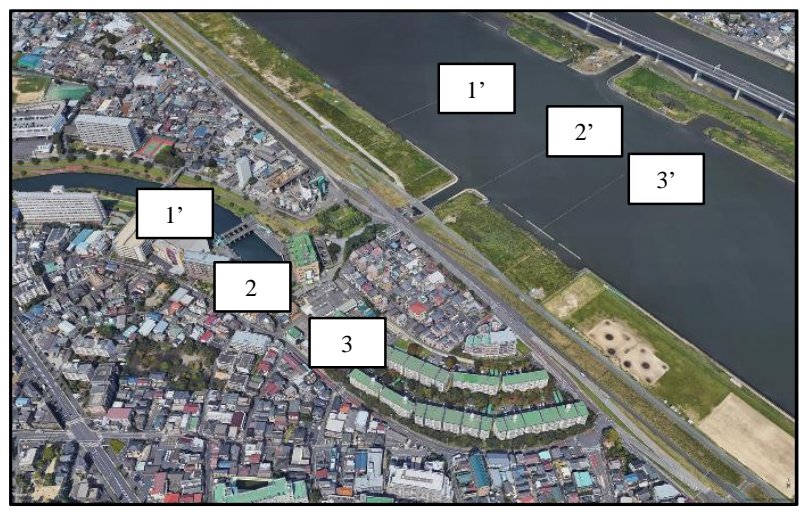

Figure 12: Cross section of Hirai \& Hirai 7-chome
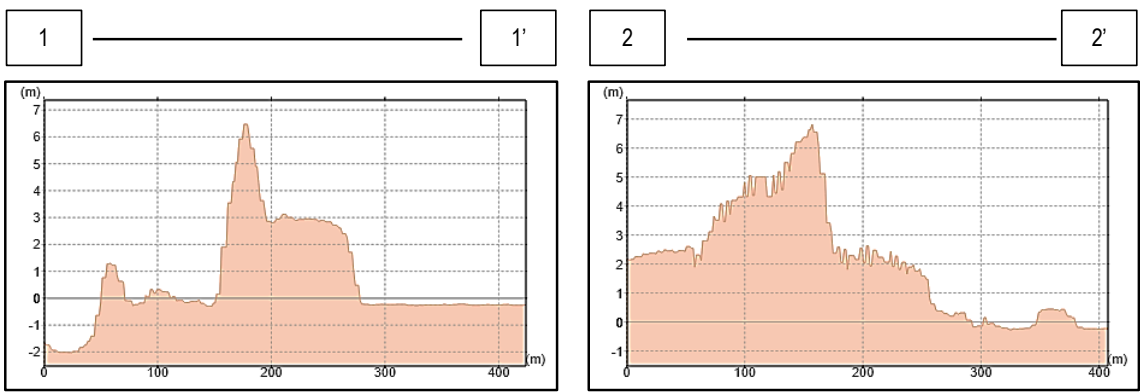

Figure 13: Elevation profile 1 and 2 of Hirai \& Hirai 7-chome 

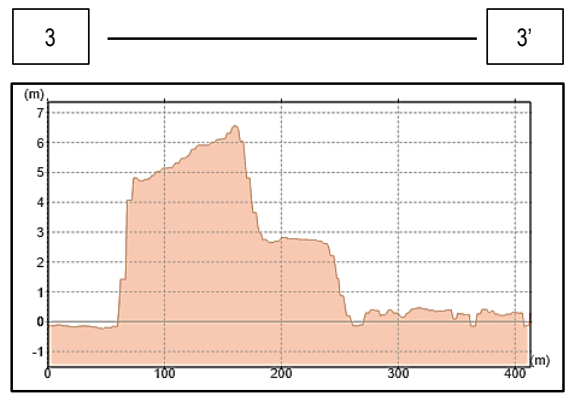

Figure 14: Elevation profile 3 of Hirai \& Hirai 7-chome

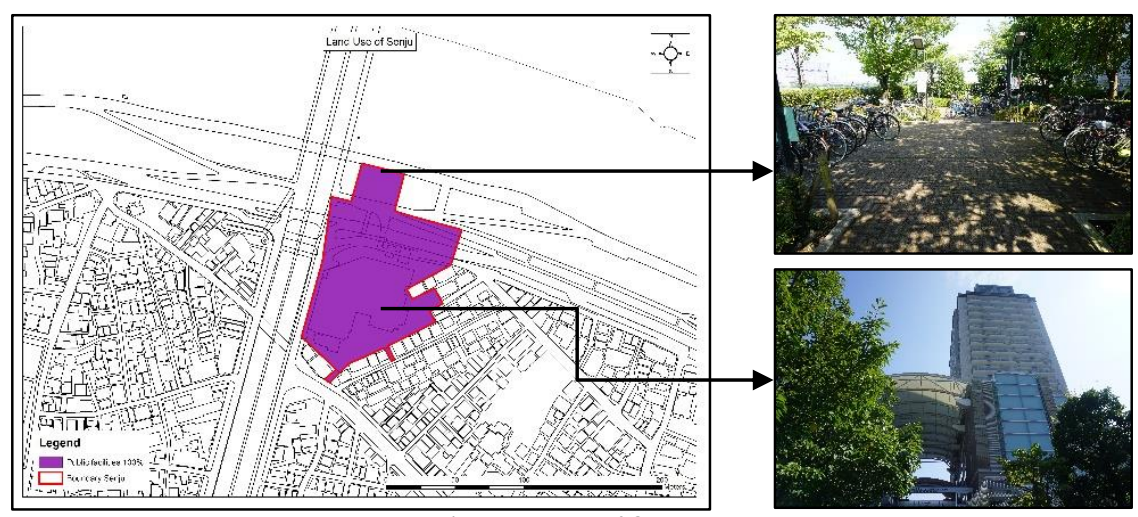

Figure 15: Land use of Senju

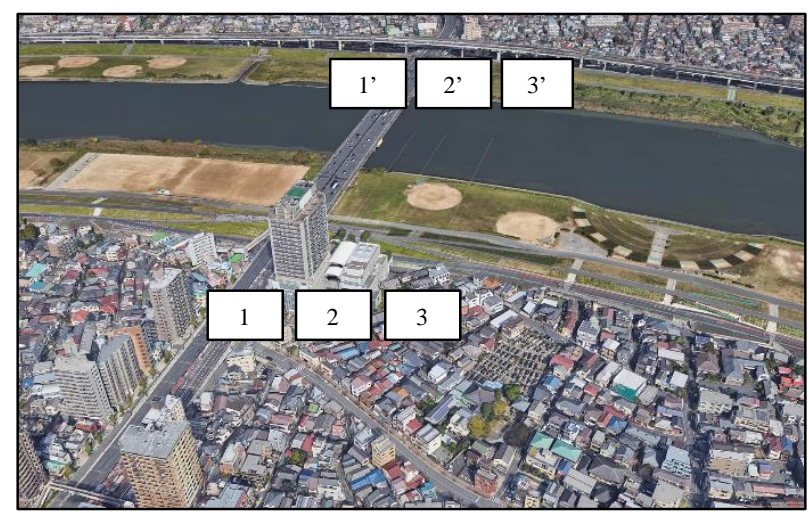

Figure 16: Cross section of Senj 

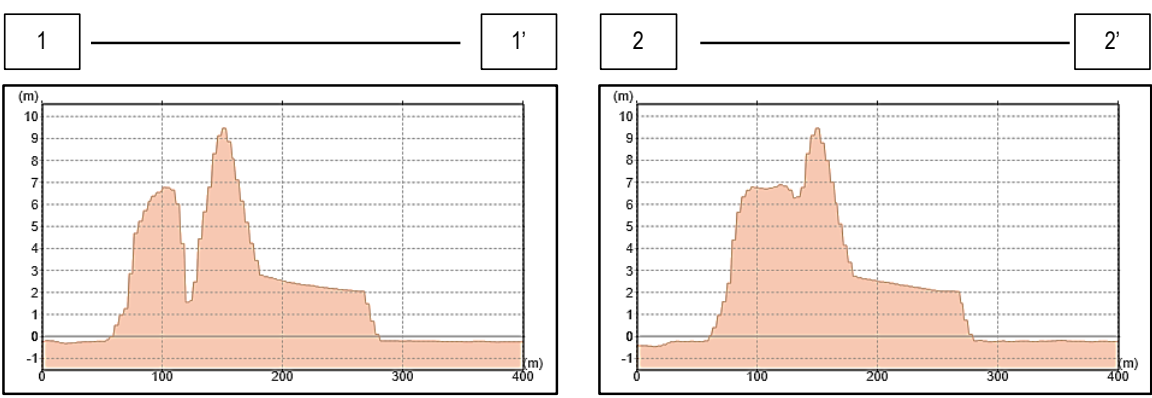

Figure 17: Elevation profile 1 and 2 of Senju
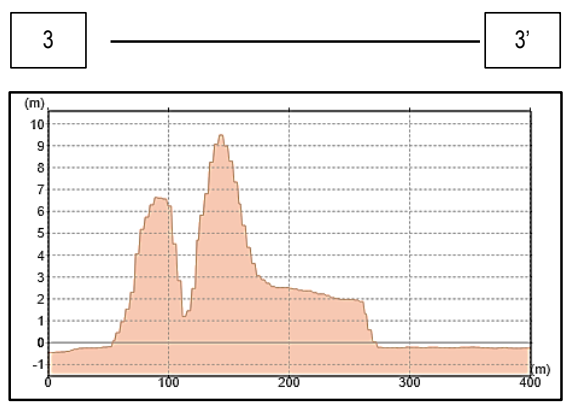

Figure 18: Elevation profile 3 of Senju

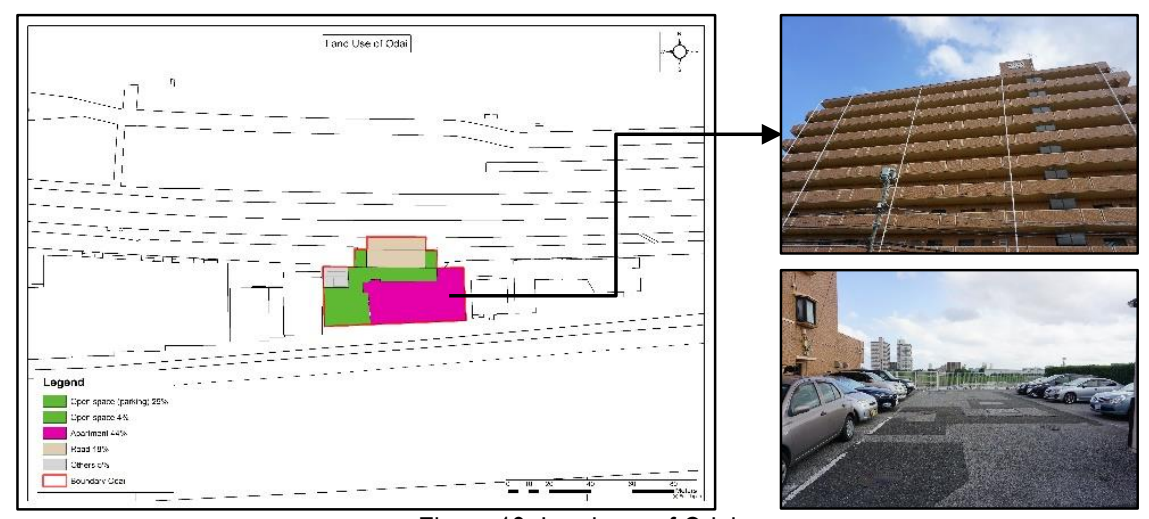

Figure 19: Land use of Odai 


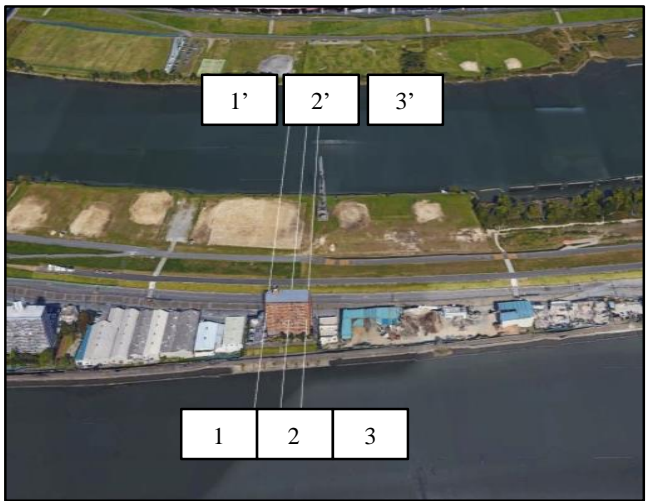

Figure 20: Cross section of Odai
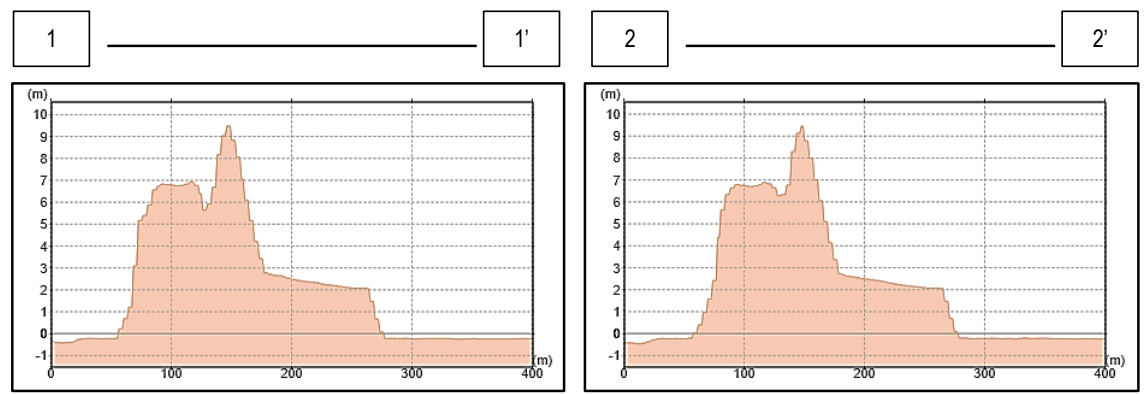

Figure 21: Elevation profile 1 and 2 of Odai
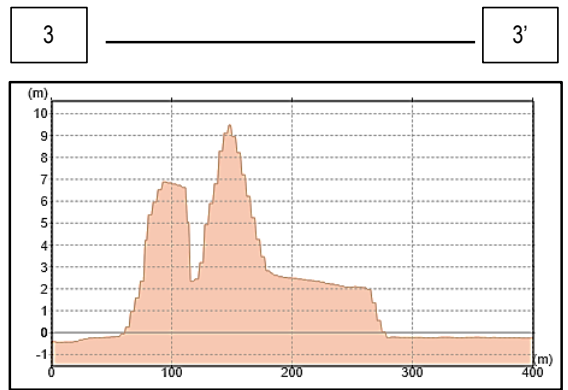

Figure 22: Elevation profile 3 of Odai 
Mabahwi, N.A., et.al. / Asian Journal of Environment-Behaviour Studies (ajE-Bs), 4(14) Sep / Dec 2019 (pp.21-52)

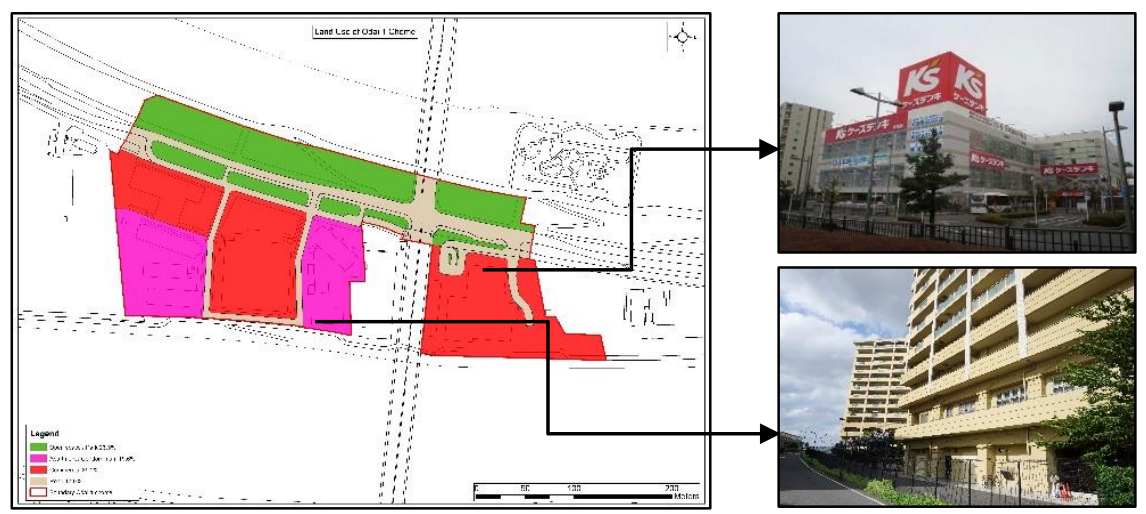

Figure 23: Land use of Odai 1-chome

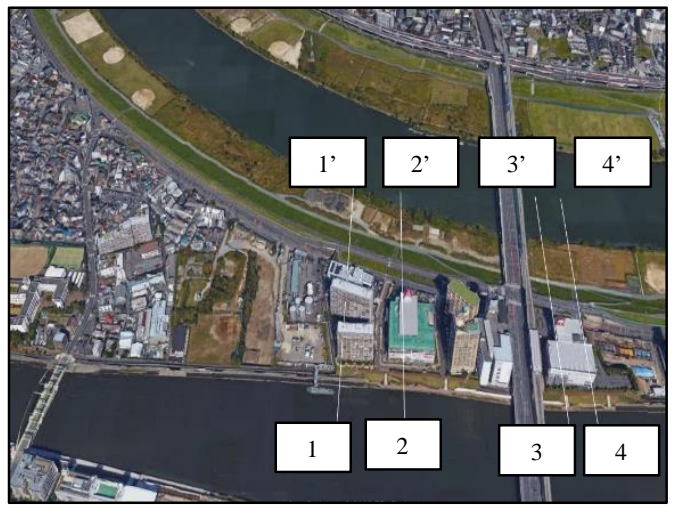

Figure 24: Cross section of Odai 1-chome
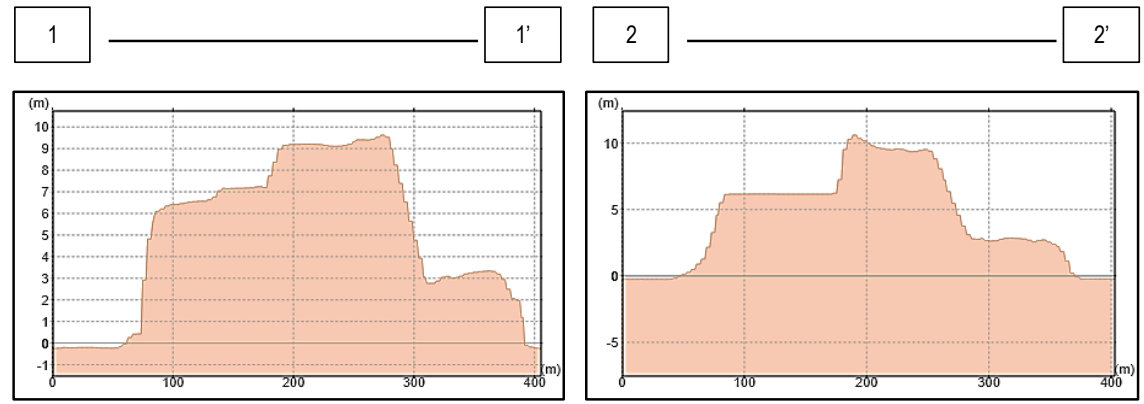

Figure 25: Elevation profile 1 and 2 of Odai 1-chome 
Mabahwi, N.A., et.al. / Asian Journal of Environment-Behaviour Studies (ajE-Bs), 4(14) Sep / Dec 2019 (pp. 21-52)
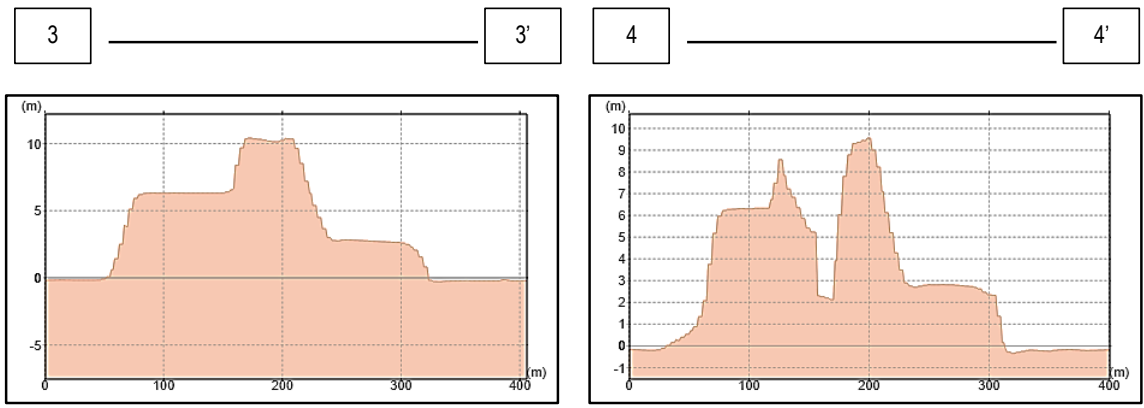

Figure 26: Elevation profile 3 and 4 of Odai 1-chome

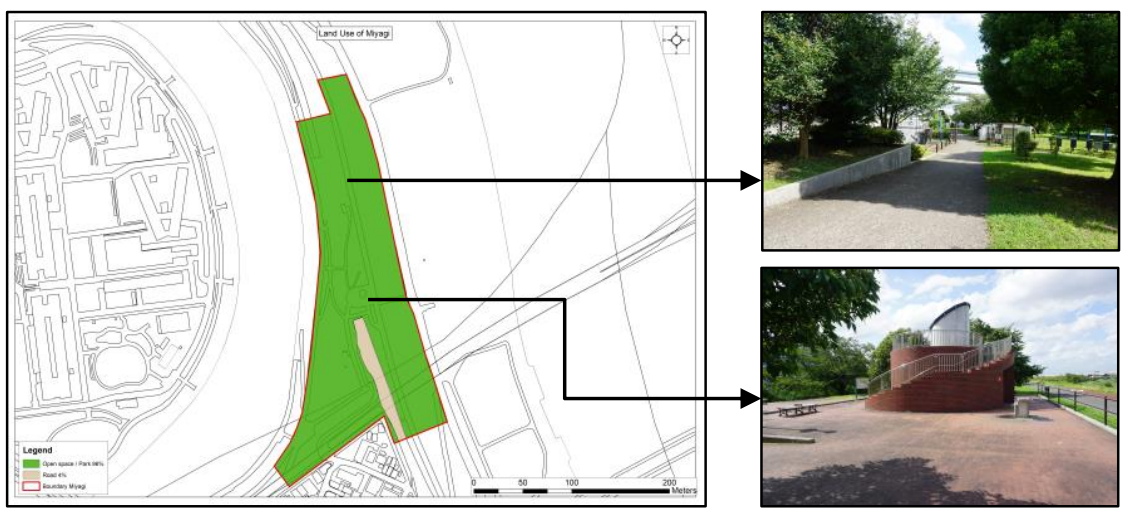

Figure 27: Land use of Miyagi

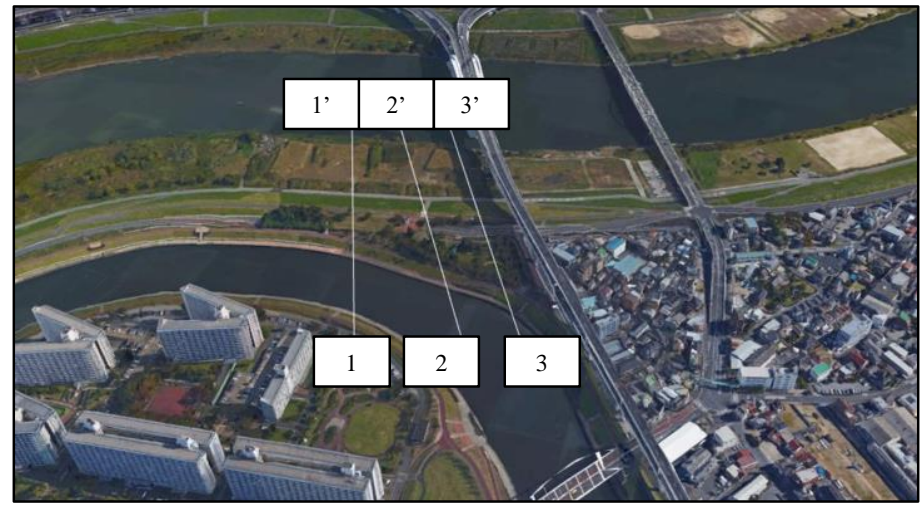

Figure 28: Cross section of Miyagi 
Mabahwi, N.A., et.al. / Asian Journal of Environment-Behaviour Studies (ajE-Bs), 4(14) Sep / Dec 2019 (pp.21-52)
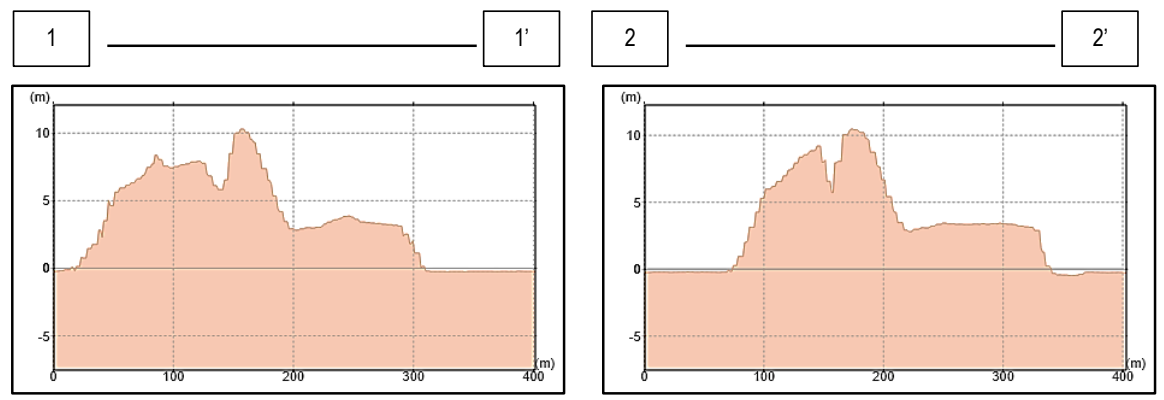

Figure 29: Elevation profile 1 and 2 of Miyagi

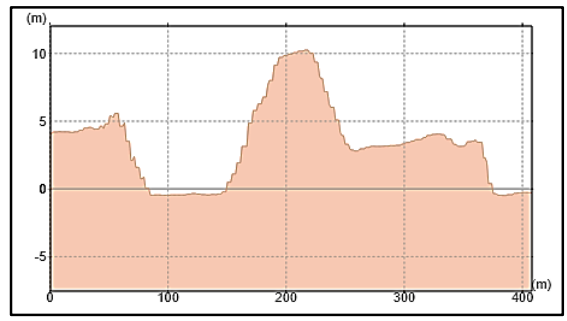

Figure 30: Elevation profile 3 of Miyagi 
Mabahwi, N.A., et.al. / Asian Journal of Environment-Behaviour Studies (ajE-Bs), 4(14) Sep / Dec 2019 (pp. 21-52)

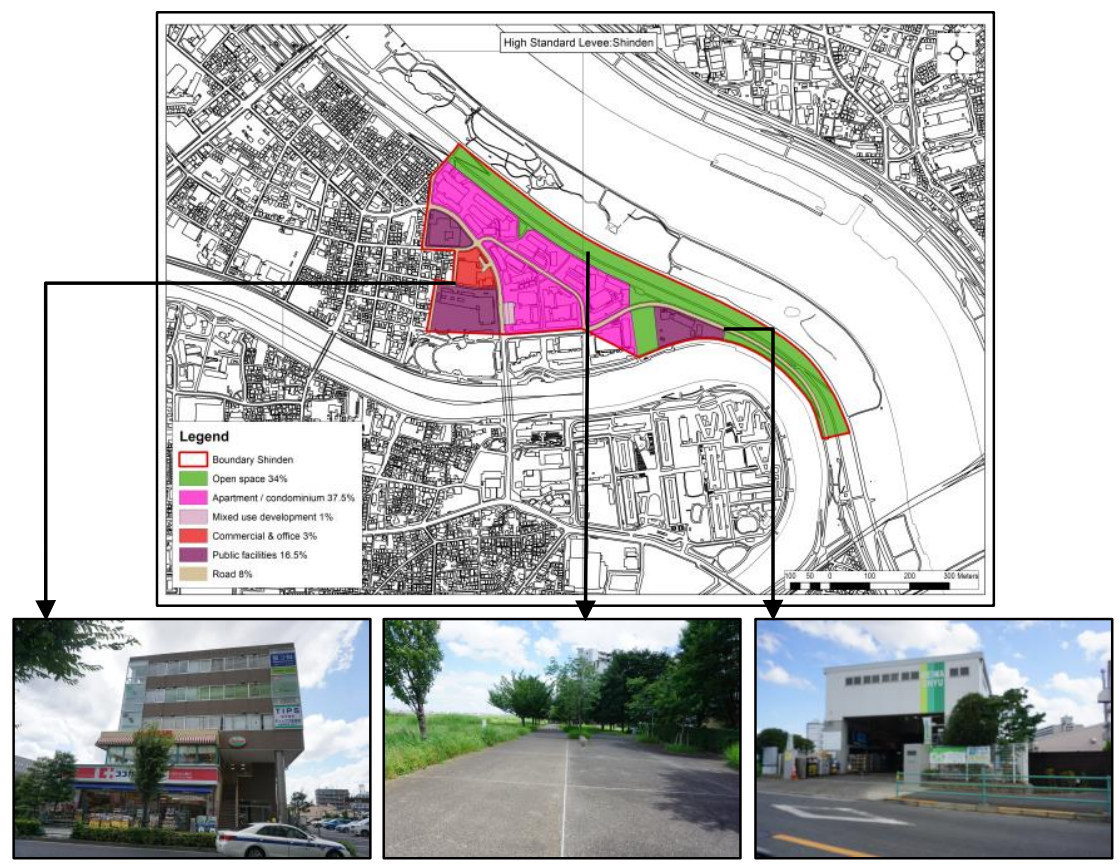

Figure 31: Land use of Shinden

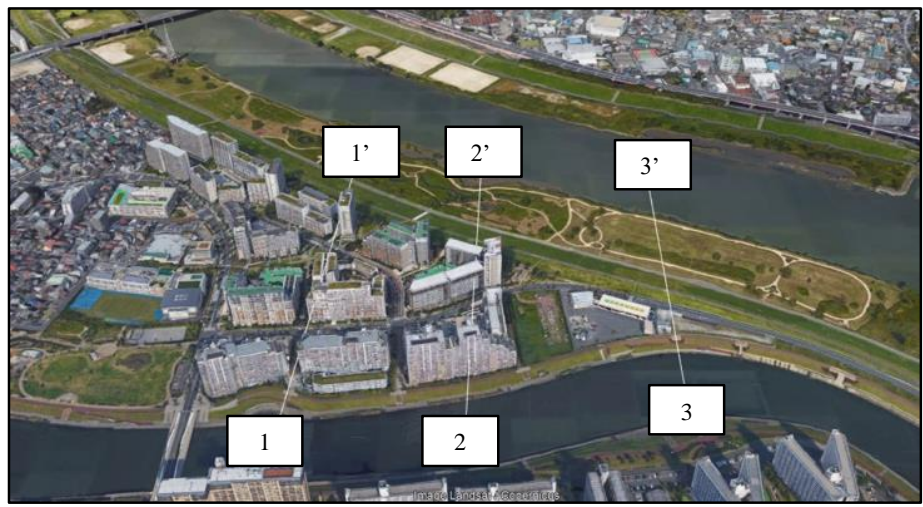

Figure 32: Cross section of Shinden 
Mabahwi, N.A., et.al. / Asian Journal of Environment-Behaviour Studies (ajE-Bs), 4(14) Sep / Dec 2019 (pp.21-52)
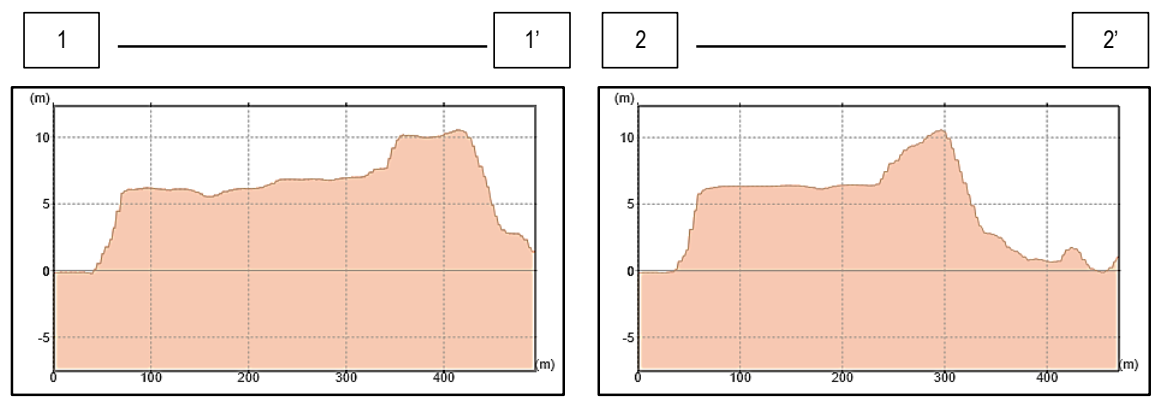

Figure 33: Elevation profile 1 and 2 of Shinden
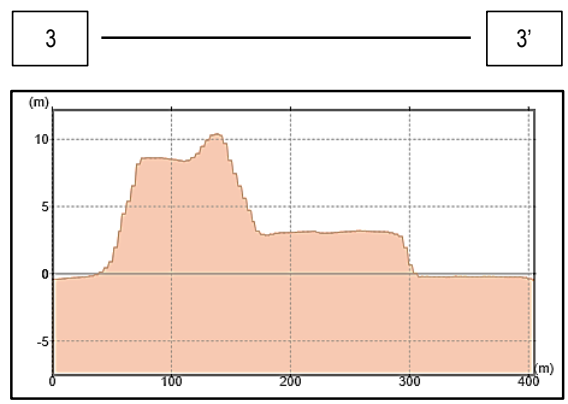

Figure 34: Elevation profile 3 of Shinden 
Mabahwi, N.A., et.al. / Asian Journal of Environment-Behaviour Studies (ajE-Bs), 4(14) Sep / Dec 2019 (pp. 21-52)

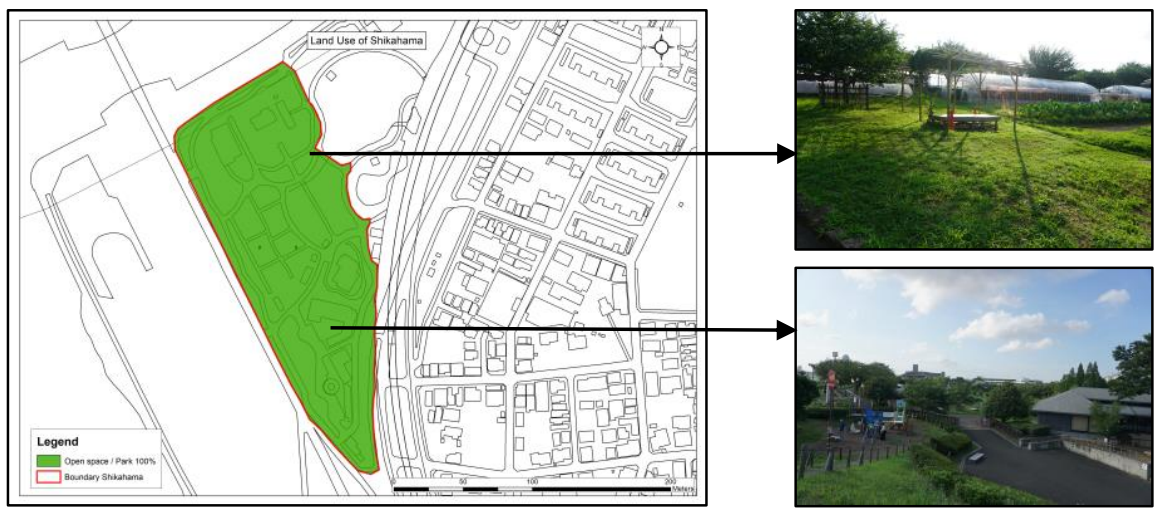

Figure 35: Land use of Shikahama

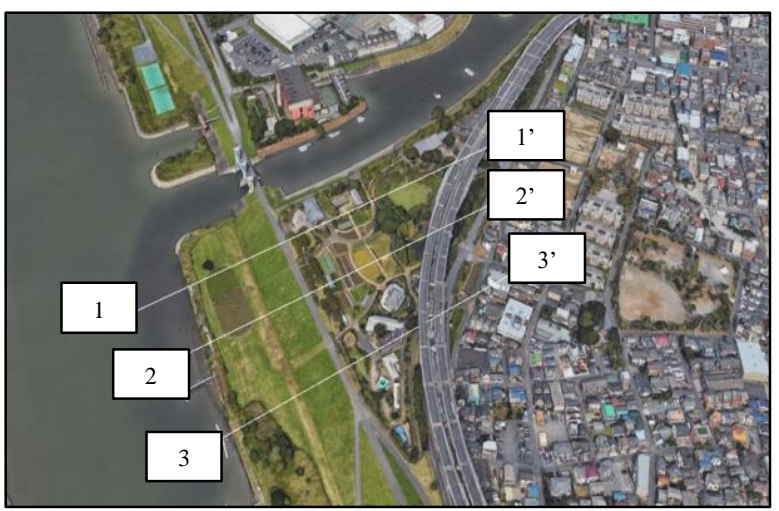

Figure 36: Cross section of Shikahama
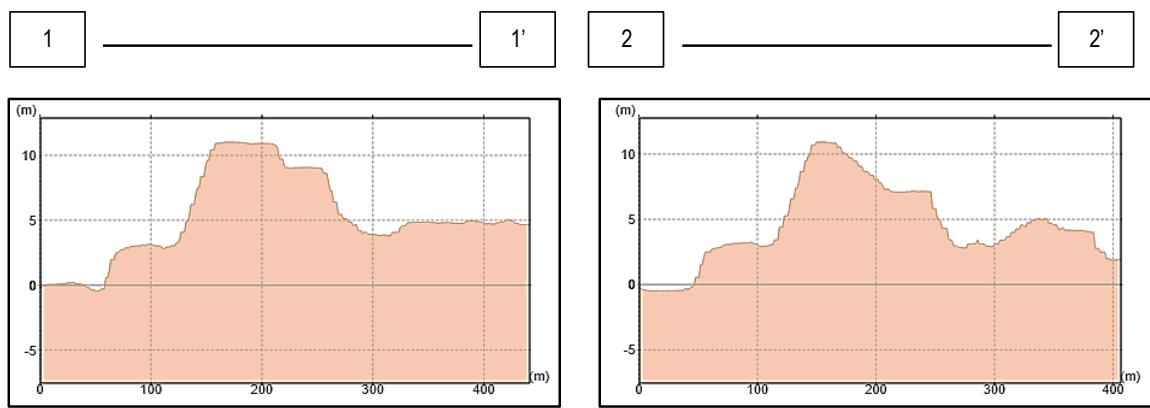

Figure 37: Elevation profile 1 and 2 of Shikahama 
Mabahwi, N.A., et.al. / Asian Journal of Environment-Behaviour Studies (ajE-Bs), 4(14) Sep / Dec 2019 (pp.21-52)
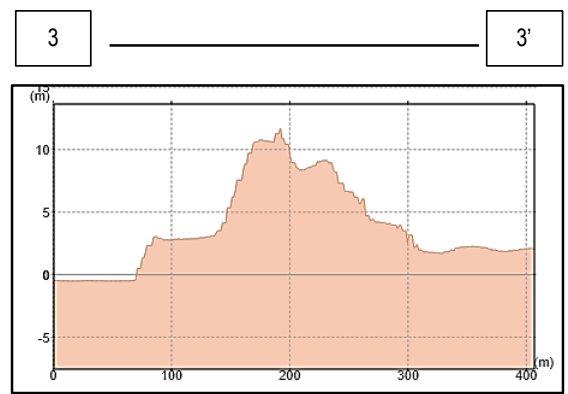

Figure 38: Elevation profile 3 of Shikahama

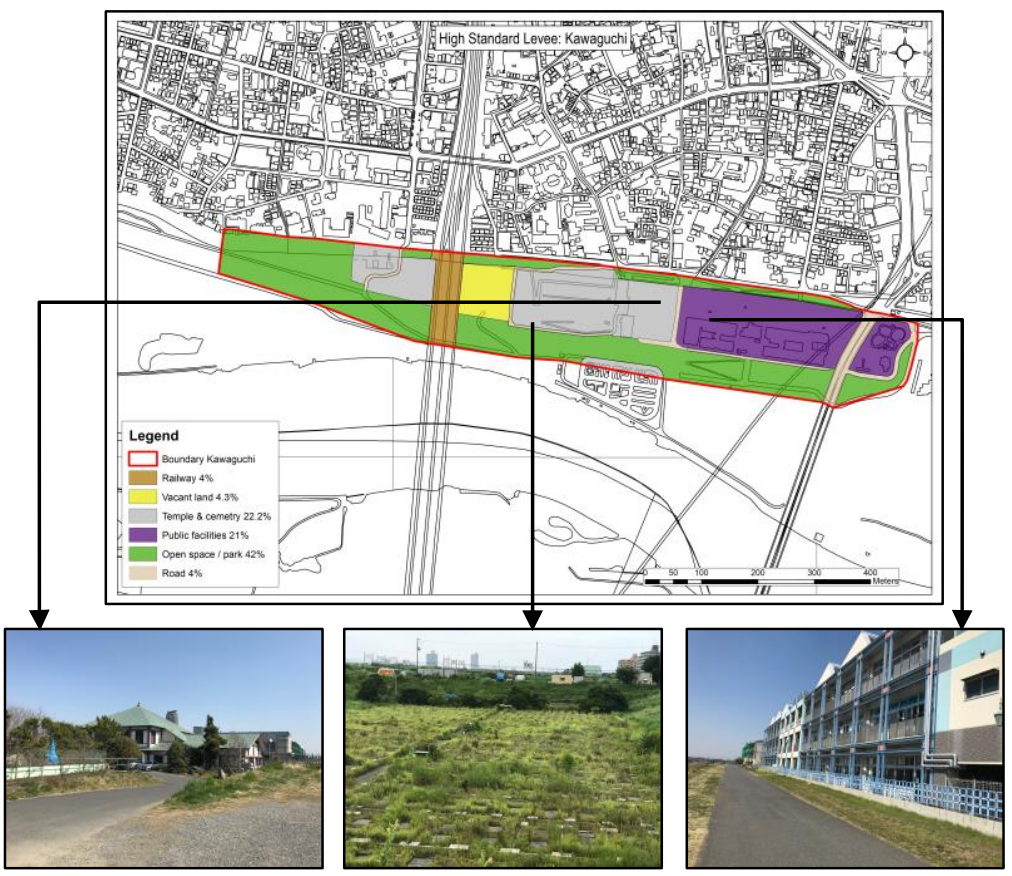

Figure 39: Land use of Kawaguchi 
Mabahwi, N.A., et.al. / Asian Journal of Environment-Behaviour Studies (ajE-Bs), 4(14) Sep / Dec 2019 (pp. 21-52)

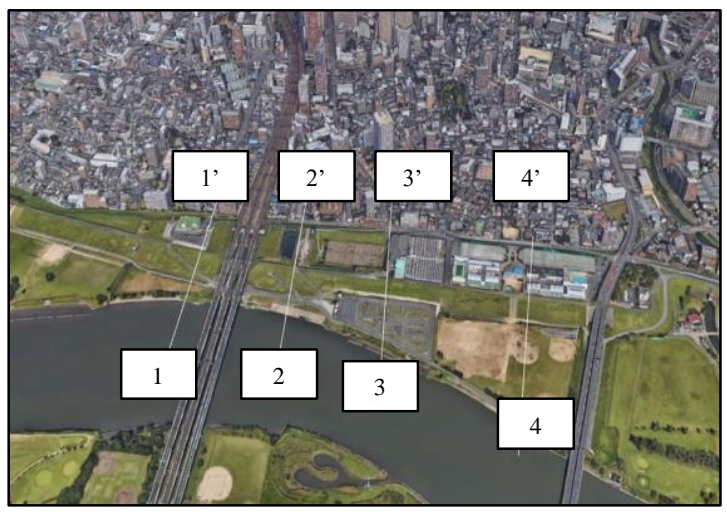

Figure 40: Cross section of Kawaguchi
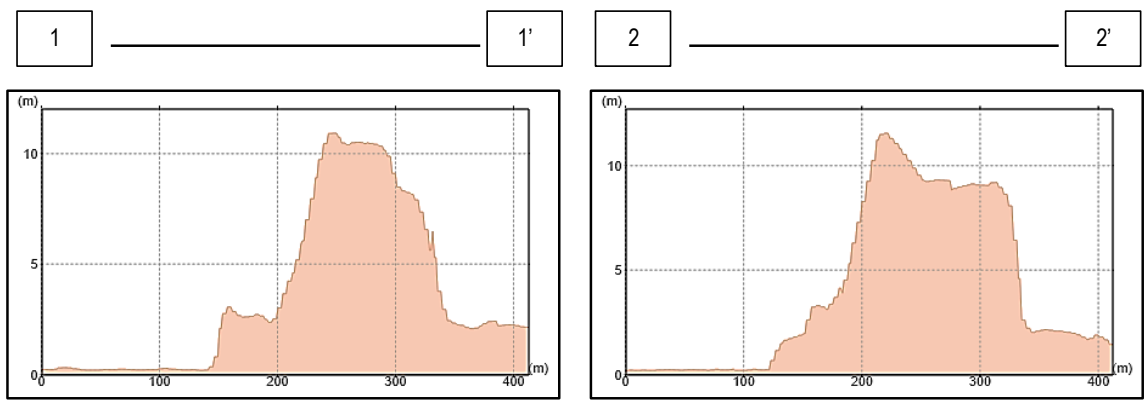

Figure 41: Elevation profile 1 and 2 of Kawaguchi
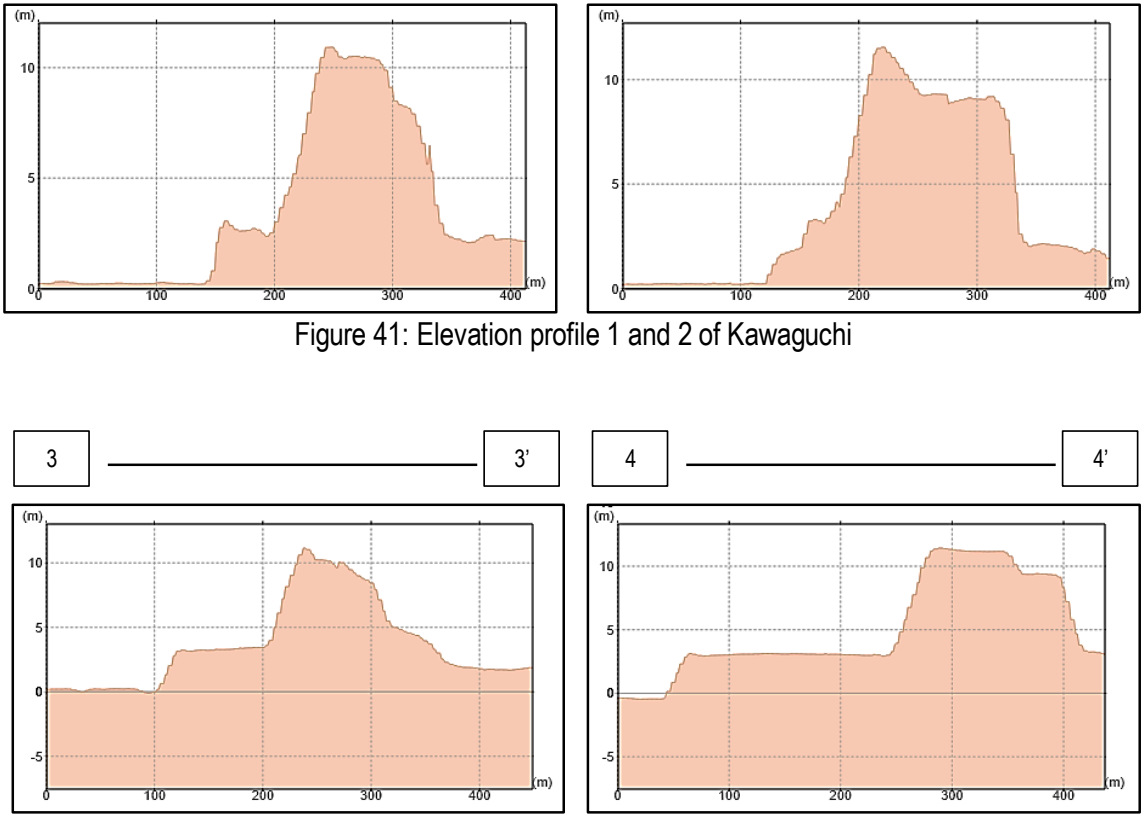

Figure 42: Elevation profile 3 and 4 of Kawaguchi 


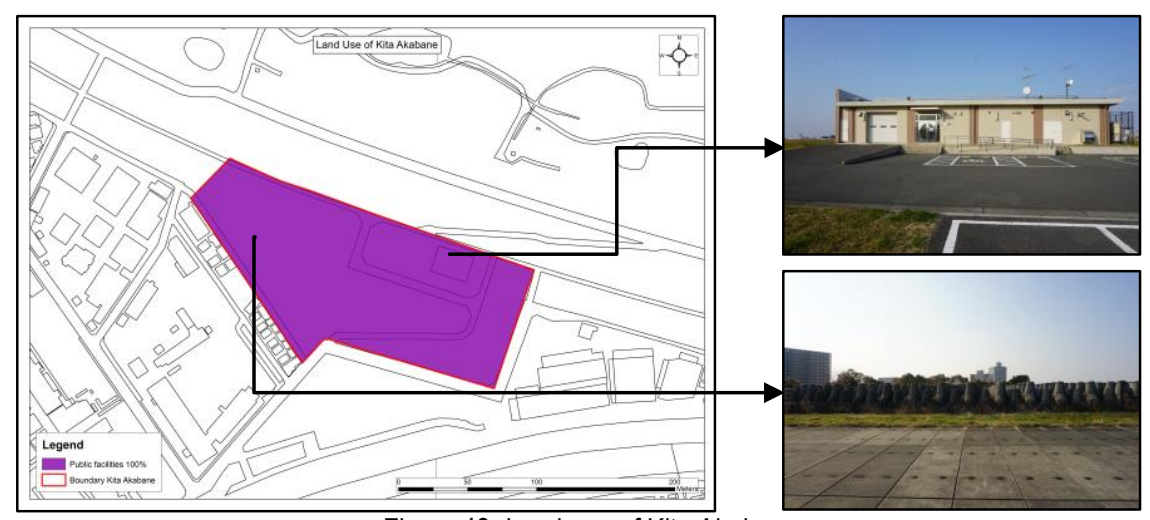

Figure 43: Land use of Kita Akabane

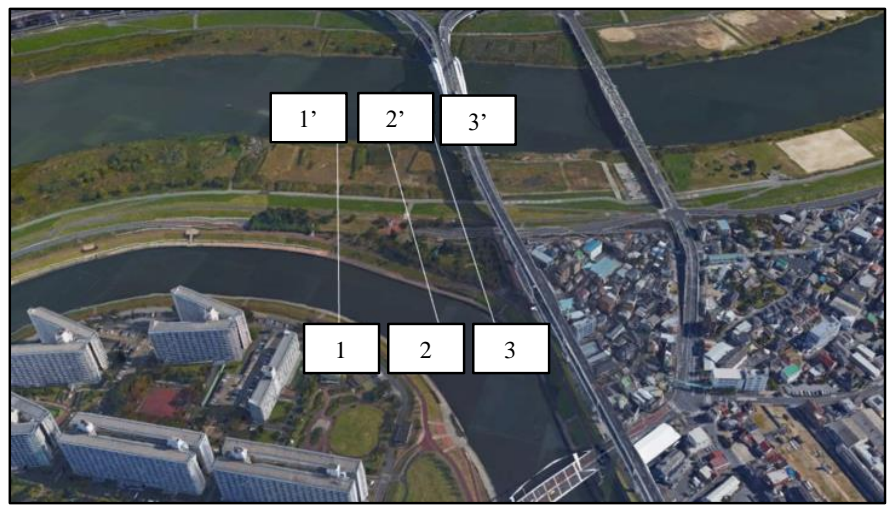

Figure 44: Cross section of Kita Akabane
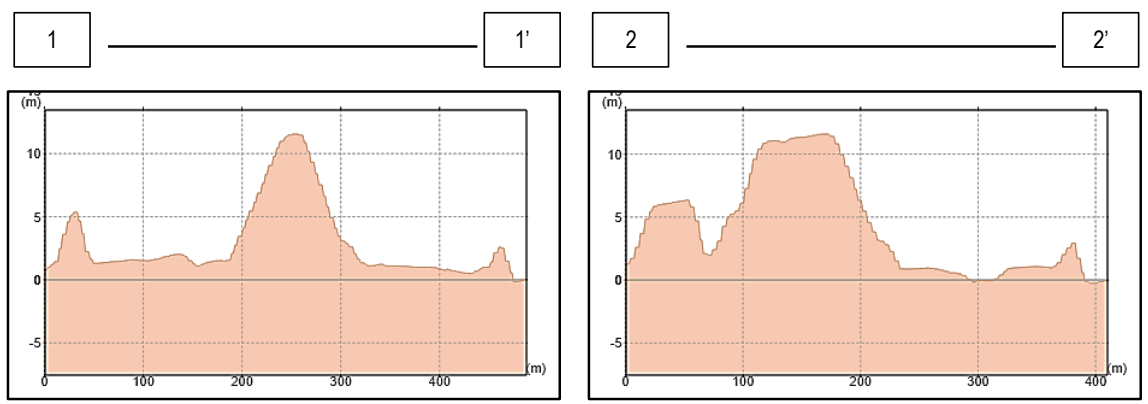

Figure 45: Elevation profile 1 and 2 of Kita Akabane 
Mabahwi, N.A., et.al. / Asian Journal of Environment-Behaviour Studies (ajE-Bs), 4(14) Sep / Dec 2019 (pp. 21-52)
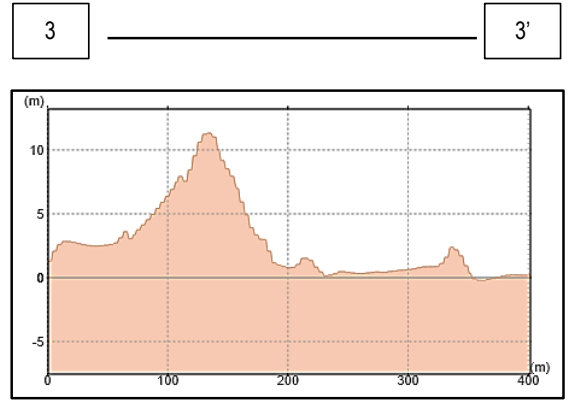

Figure 46: Elevation profile 3 of Kita Akabane

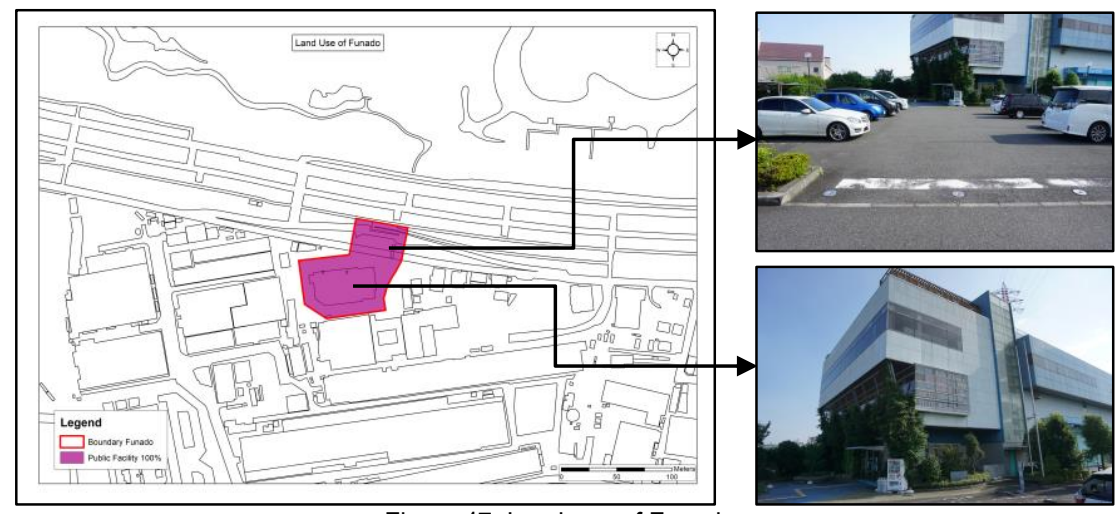

Figure 47: Land use of Funado

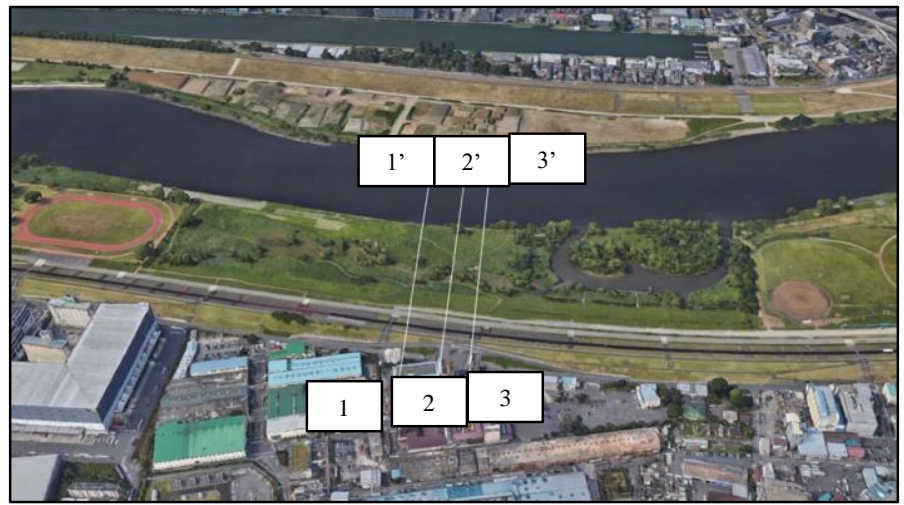

Figure 48: Cross section of Funado 
Mabahwi, N.A., et.al. / Asian Journal of Environment-Behaviour Studies (ajE-Bs), 4(14) Sep / Dec 2019 (pp.21-52)
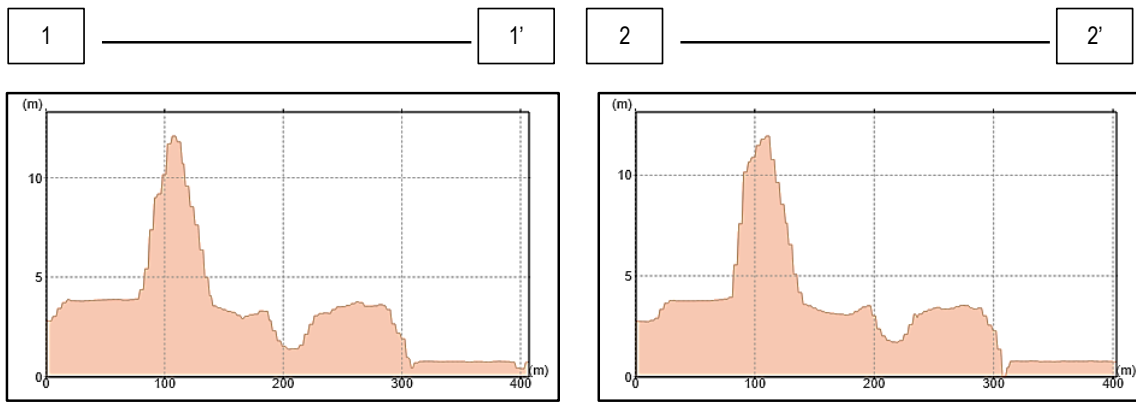

Figure 49: Elevation profile 1 and 2 of Funado

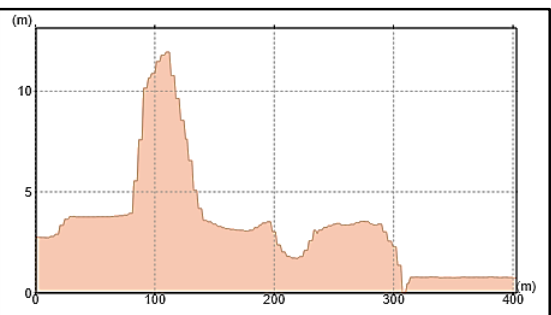

3
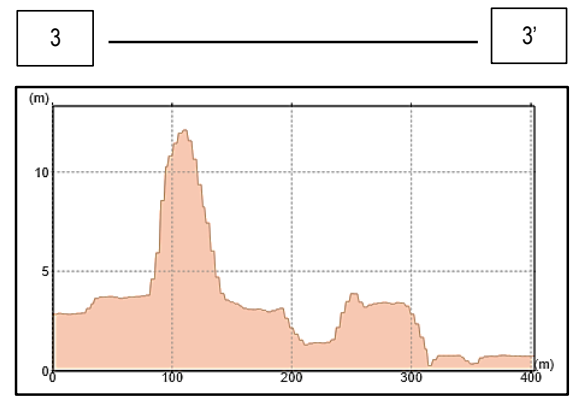

Figure 50: Elevation profile 3 of Funado

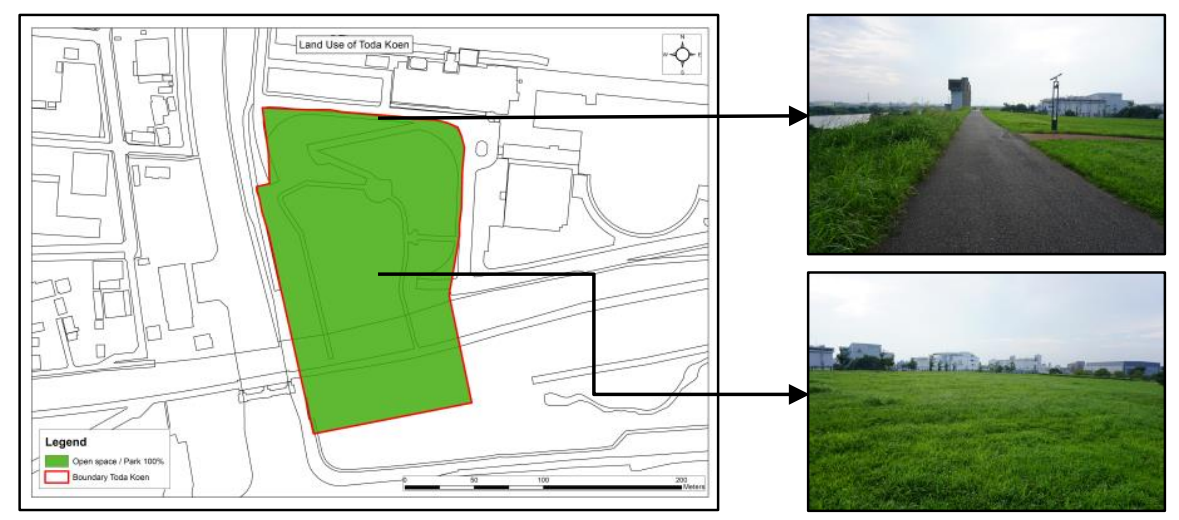

Figure 51: Land use of Toda Koen 
Mabahwi, N.A., et.al. / Asian Journal of Environment-Behaviour Studies (ajE-Bs), 4(14) Sep / Dec 2019 (pp. 21-52)

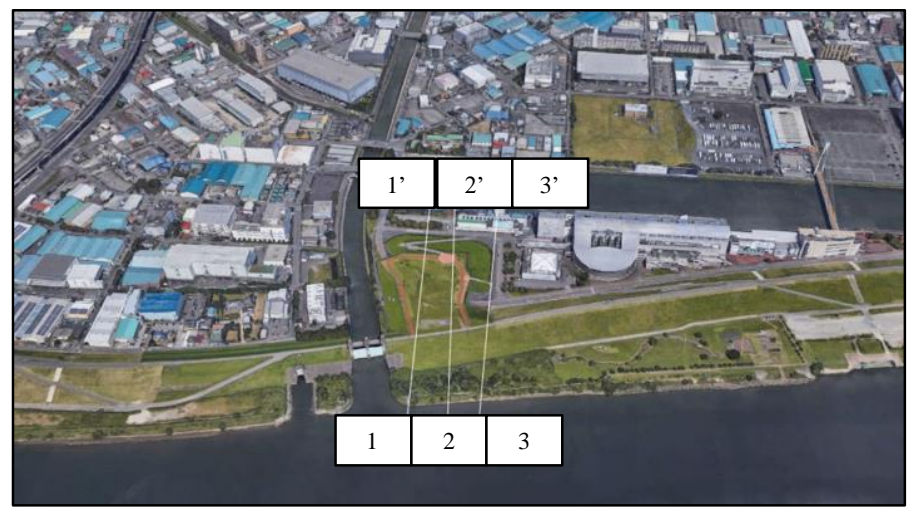

Figure 52: Cross section of Toda Koen
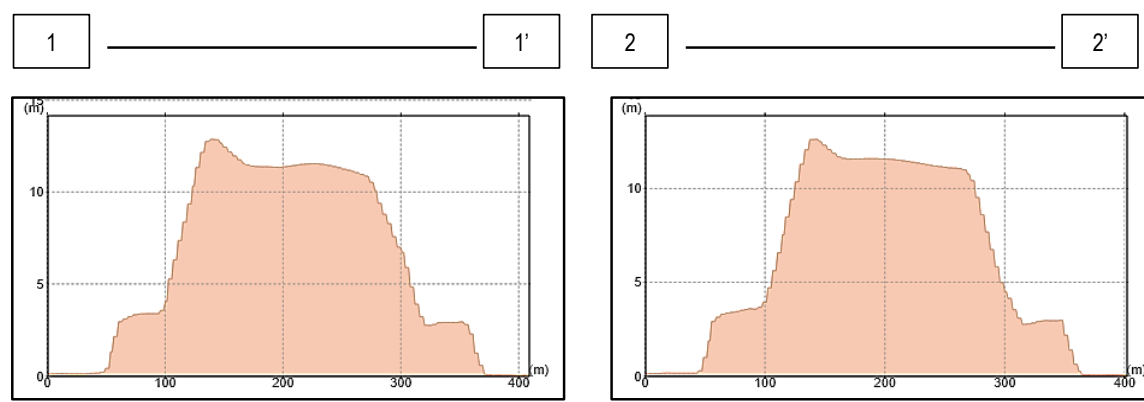

Figure 53: Elevation profile 1 and 2 of Toda Koen
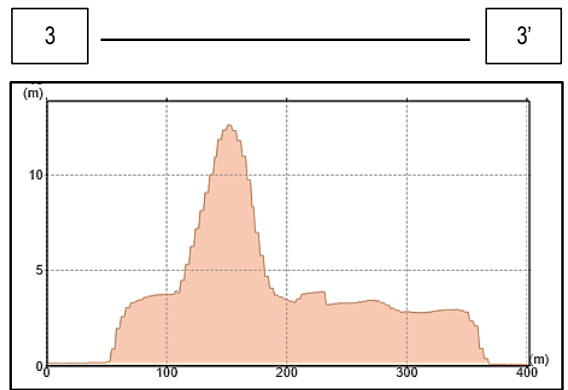

Figure 54: Elevation profile 3 of Toda Koen 


\subsection{Open spaces as an evacuation area}

This study analysed all possible open space as an evacuation area in super levee's districts. Fourteen super levees along Arakawa River were selected for this analysis: Shinsuna, Komatsugawa, Hirai and Hirai 7-chome, Senju, Odai, Odai 1-chome, Miyagi, Shinden, Shikahama, Kawaguchi, Kita Akabane, Funado and Toda Koen. Possible open space as evacuation area were determined by observation during the site visit and each space was calculated and analysed by using GIS. This study used assumption analysis to exclude trees, shrubs, built up in open space such as benches, toilet, fountain and others. For example, based on assumption, $10 \%$ of the park in Miyagi cannot be used as evacuation space due to trees. In minimising the possible error of assumption, calculation of area was made by overlaying Landsat image with ArcMap. This technique is to ensure the deduction percentage of open area is reasonable. Also, to calculate the number of possible evacuees, occupancy analysis was used with minimum space for each evacuee is $2 \mathrm{~m}^{2}$. Then, by using crosssection, the elevation of all evacuation area was determined to reconfirm the suitability as an upper land evacuation area (refer to Table 3).

Contrary to the super levee's concept to have open space as an evacuation area, this study found that Hirai and Hirai 7-chome, Senju, Odai, Odai 1-chome, Kita Akabane and Funado were not developed with open spaces. Therefore, there is a need to re-evaluate the concept of open space as evacuation space for these sites and take into consideration the use of parking lots, bicycle lots, sidewalks and residential roads. As such, this study analysed parking lots, sidewalks, roads and bicycle lots as open space for temporary evacuation area in Senju, Odai, Odai 1-chome, Kita Akabane and Funado.

$65 \%$ of Shinsuna is open space (green area with no development), by excluding area with shrubs and private property, $46 \%$ of the open space (average elevation of $6.4 \mathrm{~m}$ ) can be evacuation areas with 26,868 potential evacuees. $77.5 \%$ of land use in Komatsugawa are open space, mostly park and some vacant land. There is ample space to be evacuation area, out of $241,622 \mathrm{~m}^{2}$ open space, $80 \%$ can be an evacuation area with 96,649 possible evacuees. However, for Hirai and Hirai 7-chome, there is no designated open space to be an evacuation area. The only open space available located at the river bed of Arakawa River and close to the auxiliary road (elevation approximately 6 metres). In this case, there is a possibility to use the narrow road along the residential area as a temporary evacuation area, because $40.2 \%$ of land use of the total area is residential with a narrow road. By deducting $17 \%$ of the auxiliary road, $6,397 \mathrm{~m}^{2}$ of the narrow road at the residential area of Hirai and Hirai 7-chome can be an evacuation area.

There is no public park in Kawaguchi, but the area is well-developed with open space $\left(29,491 \mathrm{~m}^{2}\right)$ of 11 metre elevation and 29,491 evacuees able to use the area.

As for Senju, it is a public facility building with no designated open space. However, this building can be an 'upper building' evacuation area. But this study does not research on the use of building as an evacuation area. Therefore, by using land use analysis, we were able to detect small bicycle lot $\left(227 \mathrm{~m}^{2}\right)$ in front of the building that can be a small temporary evacuation space. With the assumption only $20 \%\left(45 \mathrm{~m}^{2}\right)$ of the lot can be used as evacuation, only 22 evacuees can seek temporary shelter at the area. if building use was considered, perhaps enough evacuees could be accommodated. 
For Kita Akabane, despite not having open space, by observation study found that parking lots at the public facilities always empty. Therefore, about 4,100 $\mathrm{m}^{2}$ out of the parking area can be an evacuation space with 2,050 evacuees. The same case of Odai and Funado, there is no designated open space, and this study analysed its parking area to be temporary evacuation area. With the assumption only $30 \%$ of the area can be used as evacuation, about 104 evacuees can take shelter at the $207 \mathrm{~m}^{2}$ open space in Odai, and 49 evacuees can take shelter at parking lots ( $99 \mathrm{~m}^{2}$ possible evacuation space) in Funado.

Odai 1-chome consists of high rise res'idential area and commercial area. There is no designated open space or park in this area, but the sidewalks can be an evacuation area. The total area of the sidewalks $1,704 \mathrm{~m}^{2}$, with assumption $80 \%$ of the sidewalk can be used as an evacuation area, 681 evacuees can evacuate to the sidewalk.

Land use of Miyagi is $96 \%$ public recreation park, which means $90 \%$ of the total area can be evacuation space and another $6 \%$ assumption of trees etc. Shinden is a large residential area with public facilities. However, this area was not developed with large scale open space or park. In order to create ground evacuation areas, we fully utilise the small park and pedestrian walkways along the residential street at Shinden. By considering pedestrian walkways as evacuation areas, this study managed to increase the evacuation space from $9,044 \mathrm{~m}^{2}$ to $18,945 \mathrm{~m}^{2}$ (elevation of $6.5 \mathrm{~m}$ ), therefore 9,472 persons can evacuate to Shinden.

Shikahama is an agriculture park, with regards to that, calculation of evacuation taken into consideration plantation of the area. $88 \%$ of the total area possible to be evacuation area. For Toda Koen, the land use is a park, and $52 \%$ of the site can be evacuation space with 7,220 evacuees. Kawaguchi has $48,530 \mathrm{~m}^{2}$ open space. However, only $60 \%$ of the area with 11 metre elevation can be evacuation spaces. This is because the average elevation of the remaining $40 \%$ from the open space is 4.5 metre.

Unlike the other parks, there are no built-up facilities on Toda Koen. However, the remaining $48 \%$ of the area is unsuitable to be evacuation space because the average elevation is 5 metre, which is too low. Table 3 shows the availability of open space as an evacuation area and number of potential evacuees.

In short, if a disaster occurs, a sizeable number of evacuees able to evacuate to open space in Komatsugawa $(96,649$ evacuees), Miyagi $(7,200)$, Shikahama $(44,000$ evacuees) and Toda Koen (7,220 evacuees). The number of evacuees proves that super levee can create a large evacuation area on its open space.

However, results showed that the concept of 'open space as evacuation area' on super levees needs re-evaluation for Hirai and Hirai 7-chome, Senju, Odai, Odai 1-chome, Shinden, Kita Akabane and Funado and consider the use of buildings or roads as evacuation space because these areas not developed with open space. Considering that we use parking lots, bicycle lots, sidewalks and roads as an evacuation area and 3,100 evacuees could evacuate to narrow roads in Hirai and Hirai 7-chome, 22 evacuees can evacuate to small bicycle lots in Senju, 681 evacuees to sidewalks in Odai 1-chome, 104 evacuees to parking lots in Odai and 2,050 evacuees to the parking lot in Kita Akabane, 49 evacuees to parking lot in Funado. 
Table 3: Possible evacuation spaces and evacuees on the super levee

\begin{tabular}{|c|c|c|c|c|c|}
\hline Super levee district & $\begin{array}{l}\text { Open } \\
\text { space } \\
\left(m^{2}\right)\end{array}$ & $\begin{array}{l}\text { Possible } \\
\text { evacuation } \\
\text { space }\left(m^{2}\right)\end{array}$ & $\begin{array}{l}\text { Availability of } \\
\text { evacuation area on } \\
\text { the total open space } \\
\text { (\%) }\end{array}$ & $\begin{array}{l}\text { Elevation of } \\
\text { the evacuation } \\
\text { area }(m)\end{array}$ & $\begin{array}{l}\text { Number of } \\
\text { possible } \\
\text { evacuees (2 } \\
\mathrm{m}^{2} / \text { person) } \\
\end{array}$ \\
\hline Shinsuna & 117,000 & 53,737 & 46 & 6.4 & 26,868 \\
\hline Komatsugawa & 241,622 & 193,298 & 80 & 7.4 & 96,649 \\
\hline Hirai \& Hirai 7-chome & 6,397 & 6,200 & 96 & 6.1 & 3,100 \\
\hline Senju & 227 & 45 & 20 & 6.7 & 22 \\
\hline Odai & 691 & 207 & 30 & 6.8 & 104 \\
\hline Odai 1-chome & 1,704 & 1,363 & 80 & 6.2 & 681 \\
\hline Miyagi & 15,360 & 14,400 & 90 & 10 & 7,200 \\
\hline Shinden & 9,044 & 18,945 & 90 & 6.5 & 9,472 \\
\hline Shikahama & 100,000 & 88,000 & 88 & 7.2 & 44,000 \\
\hline Kawaguchi & 48,530 & 29,491 & 60 & 11 & 14,745 \\
\hline Kita Akabane & 4,209 & 4,100 & 97 & 11.3 & 2,050 \\
\hline Funado & 331 & 99 & 30 & 7.8 & 49 \\
\hline Toda Koen & 28,000 & 14,440 & 52 & 11.5 & 7,220 \\
\hline
\end{tabular}

Note: Elevation of the evacuation areas are based on the average elevation, open space is a public park, vacant land; Narrow road in Hirai and Hirai 7-chome is considered as evacuation area; Parking lot in Kita Akabane is considered as an evacuation area; Open space in Shinden is based on green area and park; Pedestrian walkways and sidewalk in Shinden are considered as evacuation areas; Parking lots in Funado is considered as open space.

\subsection{Discussion}

This study focused on open space as an evacuation area. The remaining concept for the development of super levees was not evaluated in this study because the availability of open space is essential for evacuation, and disaster prevention is a crucial component of open space planning in Japan (Xu, 2013). Alhough super levees projects are conducted in conjunction with urban redevelopment projects, out of the 14 completed super levees, only 5 levees (Shinsuna, Komatsugawa, Miyagi, Kawaguchi, Shikahama and Toda Koen) were developed with designated open space and can function as an evacuation area. To be more specific, only 4 levees were developed as parks and 1 levee as a public facilities that can accommodate evacuees in the open spaces with a significant percentage of space availability (refer to Table 3). Super levees developed as residential (Hirai and Hirai 7-chome, Odai and Shinden), public facilities (Senju, Kita Akabane and Funado), and commercial (Odai 1chome), were not equipped with open space for evacuation. This proves that the actual construction of super levees does not comply with the development concept of having open space as an evacuation area, and is definitely in contrast with published promotions of super levees from the government. In other words, redevelopment projects conducted tandem with super levees do not consider evacuation in case of disaster as the planning element (by referring to the case of Hirai and Hirai 7-chome, Odai, Senju and Kita Akabane).

Therefore, there is a need to re-evaluate the concept of 'open space as an evacuation area' and use roads, commercial buildings, high rise apartments as temporary evacuation spaces instead. Besides, further research needs to consider the availability of high rise building floors (apartments and commercial buildings) for evacuation, especially for Senju, Funado, Odai and Odai 1 -chome that currently have limited space for temporary evacuation. 


\subsection{Conclusion}

In conclusion, super levees developed with open space can undeniably provide sizeable safe upland evacuation area for nearby residents. However, the future study needs to re-evaluate the use of open space for evacuation and consider the use of high rise buildings and the road to overcoming scarce of evacuation areas for super levees developed without open space. This study hopes future development of super levee will include more open space as an evacuation area.

\section{Acknowledgements}

Our appreciation to Arakawa-Karyu River Office for the support.

\section{References}

Allan, P., \& Bryant. (2010). The critical role of open space in earthquake recovery: a case study. EN: Proceedings of the 2010 NZSEE Conference, 1-10.

Arakawa-Karyu River Office. (2007). Super levee guidebook. Tokyo, Japan: Author.

Arakawa-Karyu River Office. (2017a). Briefing material - super levees. Tokyo, Japan: Author.

Arakawa-Karyu River Office. (2017b). Guide for the visit to the Arakawa River. Tokyo, Japan: Author.

Geospatial Information Authority of Japan (GSI). (2019). [map]. Retrieved from http://maps.gsi.go.jp/\#5/36.104611/140.084556/\&base=std\&ls=std\&disp=1\&vs=c1j0h0 kolOuOtOzOrOs0m0f1

León, J., \& March, A. (2014). Urban morphology as a tool for supporting tsunami rapid resilience: A case study of Talcahuano, Chile. Habitat International, 43, 250-262. doi:10.1016/j.habitatint.2014.04.006

Luo, P., He, B., Takara, K., Xiong, Y. E., Nover, D., Duan, W., \& Fukushi, K. (2015). Historical assessment of Chinese and Japanese flood management policies and implications for managing future floods. Environmental Science \& Policy, 48, 265-277. doi:10.1016/j.envsci.2014.12.015

McKean, C. A. (2013, December 4). Tokyo building enormous "super levees" to hold back its river. NextCity. Retrieved from https://nextcity.org/daily/entry/tokyo-is-buildingenormous-super-levees-to-hold-back-its-river

Ministry of Land, Infrastructure, Transport and Tourism. (2017a). Current status of high standard levee. Retrieved from 
http://www.mlit.go.jp/river/shinngikai_blog/koukikaku_kentoukai/dai1kai/pdf/21_genjyo.pdf

in Japanese

Ministry of Land, Infrastructure, Transport and Tourism (MLIT). (2017b). Towards the promotion of efficient maintenance of high standard levee. Retrieved from http://www.mlit.go.jp/river/shinngikai_blog/koukikaku_kentoukai/teigen.pdf in Japanese

Nakamura, H. (2016). Possibilities of neighborhood evacuation within a district in the event of a large-scale flood in a low-lying area: A case study of Shinden district in Tokyo. E3S Web of Conferences, 7, 19005. doi:10.1051/e3sconf/20160719005

Stalenberg, B., \& Kikumori, Y. (2009). Urban flood control on the rivers of Tokyo metropolitan. In Urban water in Japan (11th ed., pp. 119-141). Leiden, Netherlands: Taylor \& Francis. Edited by: Graaf \& Hooimeijer

Takahashi, Y., \& Uitto, J. I. (2004). Evolution of river management in Japan: from focus on economic benefits to a comprehensive view. Global Environmental Change, 14(8).

Takeuchi, K. (2002). Flood management in Japan-from rivers to basins. Water Int, 27, 2026.

Tokyo Metropolitan Government. (2019). Lowland rivers projects in Tokyo. Retrieved from http://www.kensetsu.metro.tokyo.jp/english/jigyo/river/04.html

$\mathrm{Xu}, \mathrm{H}$. (2013). The evolution and characteristics of the green space system planning in Japan. Modern Landscape Architecture, 138-141. Retrieved from https://pdfs.semanticscholar.org/52a1/9dd5576d118c2acb8e0efa37e43682af06 31.pdf 